\author{
RESEARCH ARTICLE \\ 10.1029/2020JC016143 \\ Key Points: \\ - The TPXO9-atlas solution and \\ K-means algorithm are used to \\ describe the asymmetries of the \\ ocean tide worldwide \\ - Symmetric tides dominate a major \\ percentage of the oceans, and \\ asymmetric tides are found in very \\ specific areas of the world
}

Correspondence to:

P. Núñez,

nunezp@unican.es

Citation:

Núñez, P., Castanedo, S., \& Medina, R. (2020). A global classification of astronomical tide asymmetry and periodicity using statistical and cluster analysis. Journal of Geophysical

Research: Oceans, 125, e2020JC016143.

https://doi.org/10.1029/2020JC016143

Received 9 FEB 2020

Accepted 21 JUL 2020

Accepted article online 28 JUL 2020

\section{A Global Classification of Astronomical Tide Asymmetry and Periodicity Using Statistical and Cluster Analysis}

\author{
P. Núñez ${ }^{1}$ iD, S. Castanedo ${ }^{2}$ iD, and R. Medina ${ }^{1}$ \\ ${ }^{1}$ IHCantabria - Instituto de Hidráulica Ambiental de la Universidad de Cantabria, C/Isabel Torres 15, Santander, Spain, \\ ${ }^{2}$ Departamento de Ciencias y Técnicas del Agua y del Medio Ambiente, E.T.S.I. de Caminos, Canales y Puertos, \\ Universidad de Cantabria, Avda. de los Castros s/n, Santander, Spain
}

\begin{abstract}
Tidal asymmetry plays a key role in the behavior of estuaries. Positive and negative asymmetries are associated with flood- and ebb-dominated estuaries, respectively. Asymmetry arises from both the interaction among the main tidal constituents and the harmonics generated when tide propagates in shallow waters. Most previous research focuses on the deformation of the tide within estuaries; however, ocean tide may show asymmetry at the estuary entrance, which implies that the boundary condition is already deformed. This fact has important implications for tide propagation, estuarine transport processes, and flow exchanges between estuaries and open oceans. In this study, the global astronomical tide is classified according to its asymmetry and periodicity. The objective is to provide a guiding framework of representative astronomical tide types (ATtypes) on a worldwide scale to be used as a reference for further research on the transport of substances in estuaries. The applied methodology is based on the use of the TPXO9-atlas global barotropic tidal solution and detailed statistical analysis. Probability density functions of the tidal elevation time derivative and the tidal form factor were extracted from TPXO9-atlas with a spatial resolution ranging from $1 / 6^{\circ}$ to $1 / 30^{\circ}$. The K-means algorithm was applied to these parameters, and 25 representative ATtypes were identified. The classification was validated with 757 worldwide tide gauge records. The results show that $11.3 \%$ of coastal areas show negative asymmetries, $11.3 \%$ positive asymmetries, while symmetric tides dominate $77.4 \%$ of coastal areas. In these areas, estuaries can show asymmetries exclusively dependent on overtides and compound tides generated during inland propagation without being externally conditioned.
\end{abstract}

Plain Language Summary The asymmetry of the tide influences the transport of substances (such as sediments and marine litter) within estuaries. Most research focuses on the deformation of the tide as it propagates through estuaries; however, the tide may show asymmetry at the entrances of estuaries, implying that the boundary condition is already deformed. This fact has important implications for tide propagation, estuarine transport processes and flow exchanges between estuaries and the open ocean. In this paper, the asymmetry of astronomical tide is characterized on a worldwide scale in the outer vicinities of estuaries to obtain a guiding framework of representative tide types. This framework can be used as a reference for further research on estuarine processes anywhere in the world.

\section{Introduction}

The asymmetry of the tide plays a key role in the behavior of estuaries (Aubrey \& Speer, 1985; Brown \& Davies, 2007; Dronkers, 1986; Friedrichs \& Aubrey, 1988; Hoitink et al., 2003; Nidzieko, 2010; Zhou et al., 2018). Tidal asymmetry refers to the distortion of tidal wave caused by the flood phase occurring faster than the ebb phase or vice versa. When the flood phase is shorter than the ebb phase, the flood currents are more intense than the ebb currents, and net transport is induced in the estuary; when the ebb phase is shorter than the flood phase, the estuary tends to export substances. This relationship has been traditionally used to explain sediment transport but can be extended to understand the transport of any other substance (e.g., marine litter and nutrients) or any other process dependent on estuarine hydrodynamics.

Tidal asymmetry arises from both the interaction of the main tidal constituents in open oceans and the harmonics generated when tide propagates in shallow-water areas (Hoitink et al., 2003; Nidzieko, 2010). Nidzieko (2010) highlighted the importance of the asymmetry imposed by the main tides in the mouth of an estuary since the asymmetry imposed in the mouth is overcome first, although the estuary morphology
(C)2020. American Geophysical Union. All Rights Reserved. 
is significant in determining the dominance of the flood phase or ebb phase in these systems. Hence, the fact that ocean tide shows asymmetry at the entrance of an estuary has significant implications for tide propagation and, consequently, in some of the most widely recognized estuarine processes. Some examples of estuarine issues that can be affected by the presence of an external asymmetry can be point out, namely, marine litter transport and distribution (Hinojosa \& Thiel, 2009; Mazarrasa et al., 2019; Núñez et al., 2019), sediment transport and morphodynamics (Boon III \& Byrne, 1981; Brown \& Davies, 2007; Dronkers, 1986; Friedrichs \& Aubrey, 1994, 1988; Gallo \& Vinzon, 2005; Ranasinghe \& Pattiaratchi, 2000), turbidity (Gallo \& Vinzon, 2005), or flushing times (Monsen et al., 2002). Therefore, a detailed analysis of this asymmetry constitutes an important starting point to study several processes on an estuarine scale.

In open oceans, the main cause of tidal asymmetry is the combined influence of the O1/K1/M2 constituents (Hoitink et al., 2003; Song et al., 2011), followed by P1/K1/S2, K1/K2 and finally Q1/K1/N2 (Song et al., 2011). In coastal areas, tide is distorted by the nonlinear effects of bottom friction and boundaries, and this distortion generates overtides (superharmonic constituents) and compound tides. Previous studies have shown that the main contribution to tidal asymmetry in shallow waters is the combined influence of the M4 overtide and the M2 constituent (Aubrey \& Speer, 1985; Song et al., 2011; Speer \& Aubrey, 1985). Nevertheless, this relationship between tidal constituents is not the only one that can influence tidal asymmetries in these areas and, in semidiurnal tidal regimes, the influences of the M6 (M2/M4/M6) (Blanton et al., 2002), MS4 (M2/S2/M4/ MS4) (Song et al., 2011), and 2MS6 (M2/S2/M6/2MS6) constituents (Byun \& Cho, 2006) can also cause asymmetry. In areas with diurnal or mixed diurnal tides, the effects of the O1/K1/M2 constituents are predominant (Hoitink et al., 2003; Ranasinghe \& Pattiaratchi, 2000; Song et al., 2011).

Asymmetry has been traditionally defined by two parameters: the ratio between the amplitudes of two tidal constituents (e.g., $a_{M 4} / a_{M 2}$ ), employed to quantify the degree of distortion, and the difference between two phases (e.g., $2 \phi_{M 2}-\phi_{M 4}$ ), used to identify the orientation (e.g., Aubrey \& Friedrichs, 1988). This harmonic parametrization enables the asymmetry derived mainly from two constituents to be described. Other studies have used probability density functions (PDFs) of tidal elevation since PDFs retain more information and hence are more suitable for characterizing long-term tidal distributions (Castanedo et al., 2007; Woodworth et al., 2005). Following this research path, Nidzieko (2010) recommended the use of a parameter related to the PDF shape, the skewness coefficient $\left(\gamma_{1}\right)$, and applied this coefficient to the tidal elevation time derivative, that is, a representative parameter of rising/falling tidal speed and, consequently, of flood/ebb currents in shore tidal estuaries. Nidzieko (2010) showed that for two tidal constituents, $\gamma_{1}$ kept the information of the traditional metric while maintaining the advantage of being applicable to any time series. Song et al. (2011) generalized this approach for any number of tidal constituents, and Nidzieko and Ralston (2012) used a variant of the skewness approach to consider asymmetry variations with changes over less than a fortnight. In summary, asymmetry can be quantified by using harmonic or statistical methods, both effective and with complementary advantages. Guo et al. (2019) found that harmonic methods are suitable for studying areas characterized by diurnal and semidiurnal regimes, while the application of statistical methods is relevant in mixed tidal regimes.

Most of the existing studies on asymmetry are based on analytical or empirical analyses of the deformation generated in a tide when it propagates through an estuary (Aubrey \& Speer, 1985; Blanton et al., 2002; Brown \& Davies, 2007; Byun \& Cho, 2006; Dronkers, 1986; Friedrichs \& Aubrey, 1988; Hoitink et al., 2003; Nidzieko, 2010; Nidzieko \& Ralston, 2012; Ranasinghe \& Pattiaratchi, 2000). However, the direct effect of asymmetry originating in the open ocean as a boundary condition for the transport of substances in estuaries has not yet been studied in depth. Hoitink et al. (2003) performed a theoretical study and provided an inventory of tidal constituents that contribute to asymmetry, including not only overtides and compound tides but also main tidal constituents. Song et al. (2011) developed a global approach for investigating asymmetry in the open ocean using the TPXO7-atlas solution with a spatial resolution of $0.25^{\circ}$ and identified the constituents responsible for asymmetry worldwide based on the skewness parameter. They found a strong correlation between asymmetries due to different combinations of the main tidal constituents and tidal regimes (semidiurnal, mixed, and diurnal).

In the present study, the work of Song et al. (2011) was continued and extended to improve the results along coastlines by using the most current version of the TPXO9-atlas solution (Egbert \& Erofeeva, 2002) (https:// www.tpxo.net/). Although TPXO7-atlas is suitable for describing the tide in open oceans, its spatial 
resolution cannot accurately simulate the tide in coastal areas. The TPXO9-atlas data set has an improved tidal accuracy compared to its previous versions (Jeon et al., 2019), and its spatial resolution $\left(1 / 30^{\circ}\right)$ allows the tide to be better characterized in coastal areas. Moreover, as a novelty, astronomical tide has been classified worldwide according to the most complete information provided by PDFs (defined by both skewness and kurtosis coefficients) of the tidal elevation time derivative. As the only hydrodynamic driver analyzed in this study is the astronomical tide before its propagation through any estuary and without considering other phenomena, the tidal elevation time derivative variable, representative of rising/falling tidel speed, can be associated to tidal currents in estuarine environments and, consequently, to the transport of substances (Hoitink et al., 2003). Despite the availability of "barotropic tidal currents" from TPXO9-atlas, the "tidal elevation time derivative" was selected as the analysis variable. Indeed, sea level data are available from tide gauges, whereas tidal current records are scarce. Therefore, hereinafter, references to flood/ebb tidal currents refer exclusively to currents due to temporal gradients in the tidal height in shore tidal estuaries. In addition, tidal periodicity was included in the analysis due to its influence on long-term transport in estuaries (Lesser, 2009). The K-means algorithm (Hastie et al., 2001) was applied to these tidal parameters to cluster astronomical tides and obtain representative types (hereinafter ATtypes) worldwide. The results were validated with data from 757 worldwide tide gauges selected from the GESLA-2 data set (Woodworth et al., 2017) to cover the world's coastal areas. Furthermore, the main tidal constituents that influences the asymmetric character of each ATtype have been identified based on the methodology proposed by Song et al. (2011). This aspect allows tidal studies to be addressed, not only from a statistical approach but also using harmonic methods, which provides additional value to the graphic guide generated herein.

The remainder of this paper is structured as follows: Section 2 describes the data sets, tools, and methods used to analyze global tide asymmetry, section 3 describes the validation process, section 4 discusses the results, and section 5 draws the main conclusions of the study.

\section{Statistical and Cluster Analysis of Global Tide Asymmetry}

\subsection{Data for Classification and Validation}

Hourly time series of astronomical tide elevations were computed from harmonic constituents provided by the TPXO global and local tidal models developed by the Oregon State University (OSU) (Egbert \& Erofeeva, 2002). These models represent an optimal least squares fit of the Laplace tidal equation to satellite altimetry data. In this study, TPXO9-atlas solution was used; this data set combines the TPXO9.v1 global solution $\left(d x=1 / 6^{\circ}\right)$ with local solutions in coastal areas, including the Arctic and Antarctic. TPXO9-atlas provides the M2, S2, N2, K2, K1, O1, P1, Q1, M4, MS4, MN4, and 2N2 harmonic constituents with a resolution of $1 / 30^{\circ}$ and the $\mathrm{Mm}, \mathrm{Mf}$, and $\mathrm{S} 1$ constituents with a resolution of $1 / 6^{\circ}$ (for more details, see https://www.tpxo. net/global/tpxo9-atlas).

A selected set of tide gauge records from the GESLA-2 (Global Extreme Sea Level Analysis Version 2) data set (www.gesla.org) was used to validate the clustering results. GESLA-2 is a quasi-global data set comprising high-frequency (hourly or more frequent) sea-level records from tide gauges distributed worldwide. Contributions to GESLA-2 come from 30 sources, 27 of which are considered public, and three are private. The main contribution comes from the University of Hawaii Sea Level Center, which provides more than one-quarter of the total station years. A total of 39,151 station years are available from 1,355 records; that is, an average of 29 years is available per record. However, the number of years varies between 1 year for many of the records and over 160 years in places such as Brest (France). The quality of this data set has been controlled by each provider and has been demonstrated in its applications in previous studies (e.g., Hunter et al., 2017; Menéndez \& Woodworth, 2010; Wahl et al., 2017). For a detailed description of this data set, refer to Woodworth et al. (2017).

\subsection{Tidal Statistics}

Probability density functions (PDFs) of the tidal elevation time derivative $(d \eta / d t)$ were generated from tidal elevation time series, obtained from TPXO9-atlas, to characterize astronomical tide worldwide (Figure 1a). A 19-year period was selected to build these $d \eta / d t$ time series and investigate the modulation of a nodal cycle. The highest spatial resolution of $1 / 30^{\circ}$ offered by TPXO9-atlas models was used to represent the high variability induced by coastlines. However, a resolution of $1 / 6^{\circ}$ was considered suitable for describing the tide in deep oceans, where there is no difference between $1 / 6^{\circ}$ resolution TPXO9 base global solution and $1 / 30^{\circ}$ 

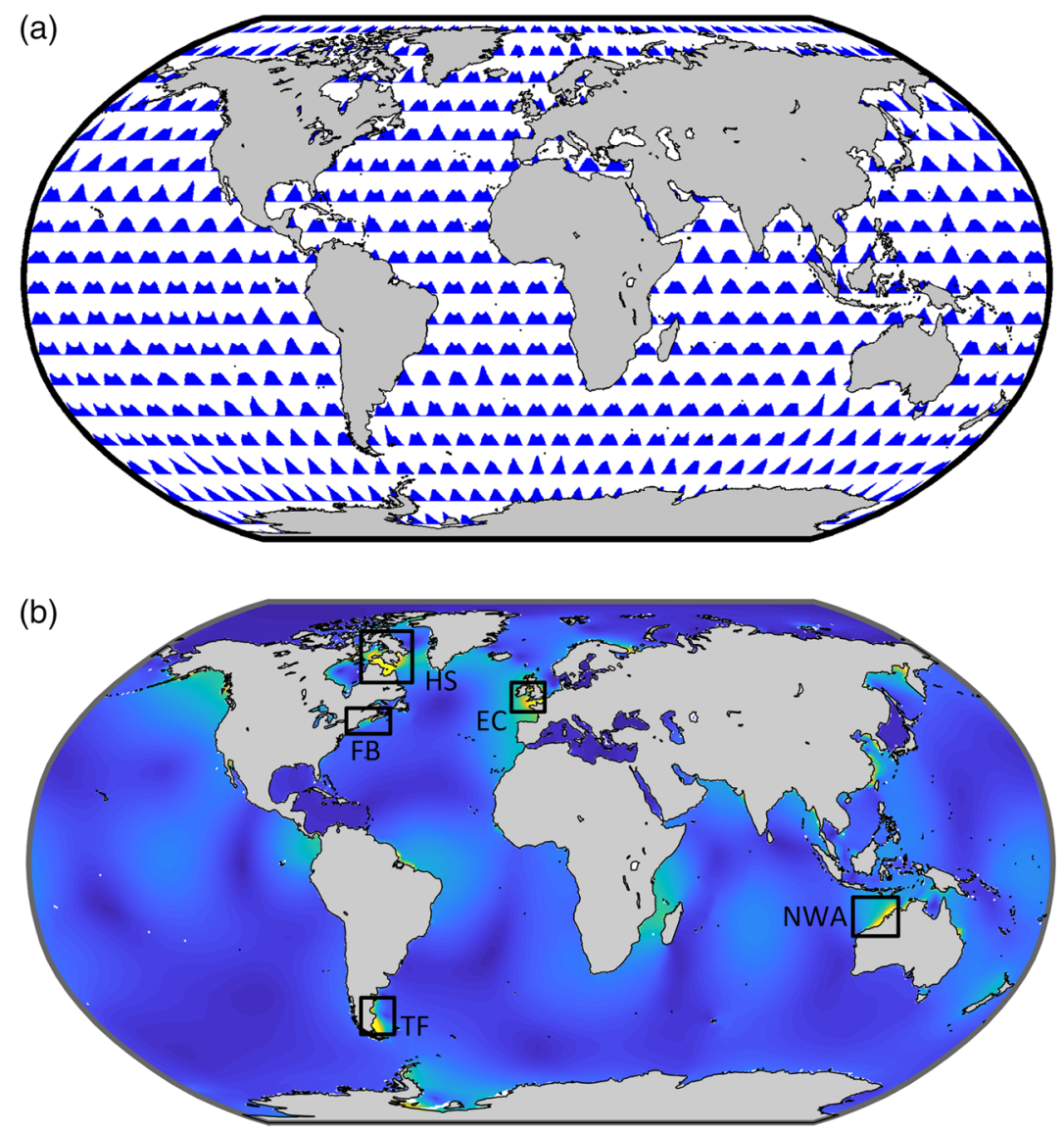

\begin{tabular}{|c|c|c|}
\hline $\begin{array}{l}\text { EC: English Chanel } \\
\text { HS: Hudson Strait }\end{array}$ & $\begin{array}{l}\text { FB: Fundy Bay } \\
\text { TF: Isla Grande de Tierra de Fuego }\end{array}$ & $\begin{array}{c}\text { NWA: NW Coast of } \\
\text { Australia }\end{array}$ \\
\hline 0.5 & 1.5 & 2 \\
\hline
\end{tabular}

Figure 1. Global distribution of the elevation time derivative $(d \eta / d t)$ of astronomical tide: (a) standardized probability density functions (PFDs) and (b) maximum magnitude ( $\left.|d \eta / d t|_{\text {max }}\right)$.

TPXO9-atlas. Twenty bins were found to be adequate for representing the PDFs of astronomical tides worldwide.

PDFs were standardized by the maximum magnitude of the tidal elevation time derivative $\left(|d \eta / d t|_{\max }\right)$ to find globally representative ATtypes. The maximum tidal elevation and therefore the rising/falling tidal speeds show large variations in different areas of the world. Figure $1 \mathrm{~b}$ shows the worldwide distribution of $|d \eta / d t|_{\max }$ and identifies some of the areas with the highest rising/falling speeds. In general, tides in the open ocean are microtidal with small rising/falling speeds, while both the tidal range and the tidal speed can be significantly higher in coastal areas. Tidal effects can be regionally amplified, and the tidal range exceeds $8 \mathrm{~m}$ in specific areas of the world (Chan \& Archer, 2003); the five regions with maximum tidal speed framed in Figure $1 \mathrm{~b}$ coincide with some of these areas. The maximum tidal speed reaches $5 \mathrm{~m} / \mathrm{s}$ in the English Chanel (Dauvin, 2012), $3.5 \mathrm{~m} / \mathrm{s}$ in the Hudson Strait (NGA 2017), 3 m/s in Fundy Bay (Karsten et al., 2008), $2.4 \mathrm{~m} / \mathrm{s}$ in Isla Grande de Tierra de Fuego (Bujalesky, 1997), and $1.5 \mathrm{~m} / \mathrm{s}$ along the NW coast of Australia (Porter-Smith et al., 2004).

To avoid potential errors derived from the discretization in bins, the PDFs were not directly clustered; instead, two statistical parameters, namely, the skewness $\left(\gamma_{1}\right)$ and kurtosis $\left(g_{2}\right)$, defining the PDF shape were used. $\gamma_{1}$, calculated as the normalized sample skewness of the tidal elevation time derivative $\left(d \eta / d t=\eta^{\prime}\right)$ 
(a) $\gamma_{1}=0.8$

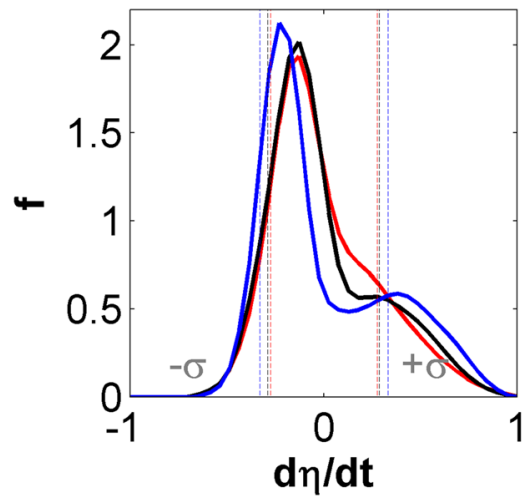

(b)

$\gamma_{1}=0$

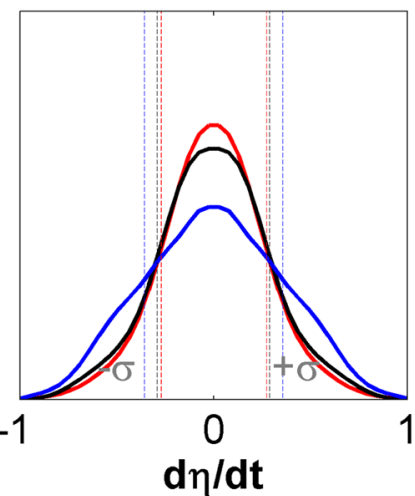

(c) $\gamma_{1}=-\mathbf{0 . 8}$

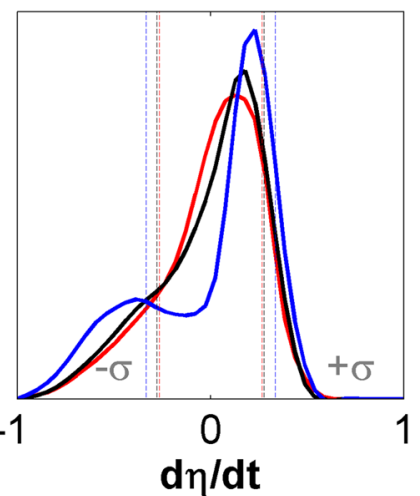

$$
-g_{2}=0.3-g_{2}=0-g_{2}=-0.5
$$

Figure 2. Examples of PDFs of $d \eta / d t$ with (a) $\gamma_{1}>0$, (b) $\gamma_{1}=0$, and (c) $\gamma_{1}<0$; associated with $g_{2}>0$ (red), $g_{2}=0$ (black), and $g_{2}<0$ (blue). The $\sigma$ boundaries for each PDF are shown as dotted lines.

(Equation 1), describes how one tail of a PDF is distributed over the other; that is, it is a measure of the distribution asymmetry:

$$
\gamma_{1} \equiv \frac{\mu_{3}}{\sigma^{3}}=\frac{\frac{1}{\tau} \sum_{t=1}^{\tau}\left(\eta_{t}^{\prime}-\overline{\eta^{\prime}}\right)^{3}}{\left[\frac{1}{\tau} \sum_{t=1}^{\tau}\left(\eta_{t}^{\prime}-\overline{\eta^{\prime}}\right)^{2}\right]^{3 / 2}},
$$

where $\mu_{3}$ is the third sample moment about the mean, $\sigma$ is the standard deviation, the square-root of the second sample moment about the mean, and $\tau$ is the number of data in the time series (hours in 19 years). This parameter was proposed by Nidzieko (2010) and was then used by Song et al. (2011) and adapted by Nidzieko and Ralston (2012) to characterize tides. If $\gamma_{1}>0$, the distribution is positively asymmetric, which implies that tidal falling speeds are more frequent than rising speeds; consequently, in shore tidal estuaries, the flood phases are shorter than the ebb phases, and flood currents are more intense (Figure 2a). Estuaries with this type of overall tidal asymmetry imposed on their mouths, where the tide is the key factor, can generally be associated with an accretive trend in such areas. It should be noted that sediment import or export depends not only on the tide but also on many other factors related to hydrodynamics (e.g., presence and type of a river discharges, temperature and salinity conditions, or currents induced by waves) and also related with sedimentary features (Ridderinkhof et al., 2000). If $\gamma_{1}<0$, the distribution is negatively asymmetric and is characterized by more intense speeds during the tidal fall than during the rise (Figure 2c). Tidal estuaries subject to these asymmetries commonly show a regressive trend in their mouths. It is worth noting that $\gamma_{1}$ can vary (by increasing, decreasing, or even changing its sign) when tide propagates in an estuary depending on the estuarine morphology and other processes, such as river contributions. Consequently, an estuary can present, for example, ebb dominance in its mouth and flood dominance inside (Nidzieko, 2010) or vice versa. However, $\gamma_{1}$ does not provide all the information contained in a PDF. Three PDFs with positive asymmetry $\left(\gamma_{1}=0.8\right)$, three symmetric PDFs $\left(\gamma_{1}=0\right)$ and three PDFs with negative asymmetry $\left(\gamma_{1}=-0.8\right)$ are shown in Figure 2. This figure illustrates how PDFs can take different shapes yet have equal skewness. The missing information is provided with the kurtosis coefficient. The convention adopted in this study is known as excess kurtosis $\left(g_{2}\right)$ corresponding to Equation 2:

$$
g_{2} \equiv \frac{\mu_{4}}{\sigma^{4}}-3=\frac{\frac{1}{\tau} \sum_{t=1}^{\tau}\left(\eta_{t}^{\prime}-\overline{\eta^{\prime}}\right)^{4}}{\left[\frac{1}{\tau} \sum_{t=1}^{\tau}\left(\eta_{t}^{\prime}-\overline{\eta^{\prime}}\right)^{2}\right]^{2}}-3,
$$

where $\mu_{4}$ is the fourth sample moment about the mean. Traditionally, there has been controversy in the interpretation of $g_{2}$ as a measure of peakedness. However, according to Balanda and MacGillivray (1988) 
and Westfall (2014), $g_{2}$ measures the concentration of data outside one standard deviation of the mean in either tail of the distribution; that is, this parameter describes how the data are distributed in the areas between the peak and tails (in the areas known as shoulders) without saying anything about the peak. Figure 2 shows how, regardless of the $\gamma_{1}$ value, the concentration of data in the shoulders moves towards the tails and increases its frequency with a decrease in $g_{2}$. Therefore, this parameter allows distributions with equal $\gamma_{1}$ to be compared and refers to the frequencies of the higher rising/falling speeds of distributions with equal $\gamma_{1}$; that is, $g_{2}$ allows to associate tides with analogous asymmetries and similar maximum tidal currents to different transport capacities in estuarine environments.

Figures $3 \mathrm{a}$ and $3 \mathrm{~b}$ show the global distributions of $\gamma_{1}$ and $g_{2}$, respectively, where different tidal patterns can be identified according to the PDF shape. The largest $\gamma_{1}$, both positive and negative, are in very specific areas of the world that are relatively adjacent (warm-colored areas for $\gamma_{1}>0$ and cold-colored areas for $\gamma_{1}<0$ in Figure 3a). It is worth noting that the most asymmetric tides are concentrated in the northern and southern areas of the Pacific Ocean, the area between the Gulf of Mexico and the Caribbean Sea, the coastal areas of the United Kingdom, the North Sea, the Mediterranean Sea, the Arabian Sea, the SW coastline of Australia, the China Seas, and the Japan Sea. As shown in Figure 3b, $g_{2}$ adopts average values of approximately -0.5 in these areas. In contrast, $\gamma_{1}$ close to zero dominate the central area of the Pacific Ocean, the Atlantic Ocean, and the central area of the Indian Ocean, which coincide with the areas where $g_{2}$ adopts its relatively low values $\left(g_{2}<-0.8\right)$. The highest values of $g_{2}$ are around 0 and reaching 0.8 in some specific areas of the world, such as the Patagonian Shelf. Such $g_{2}$ values are located in the proximity of the tidal amphidromic points where tidal amplitudes and, therefore, tidal speeds are null. Figure $3 \mathrm{c}$ shows a scatter plot of $\gamma_{1}-g_{2}$ and the frequencies of different types of PDFs around the world according to these parameters. Some considerations can be drawn from this figure. On the one hand, both parameters show well-defined limits, namely, -0.9 and 0.9 for $\gamma_{1}$ and -1.5 and 0.8 for $g_{2}$. On the other hand, symmetric distributions $\left(\left|\gamma_{1}\right|<0.1\right)$ can show kurtosis within the entire available range $[-1.5,0.8]$, indicating wide variations in the frequencies of $d \eta / d t$, that is, from high frequencies for $g_{2}$ of approximately -1.5 to low frequencies for $g_{2}$ near 0.8 . However, as the asymmetry of a distribution increases $\left(\left|\gamma_{1}\right|>0.1\right)$, the range of $g_{2}$ narrows around higher values $[-0.2$, 0.8]. Moreover, the most frequent tidal distributions in the world are symmetric $\left(\left|\gamma_{1}\right|<0.1\right)$ and have small kurtosis $\left(\gamma_{1}<-0.8\right)$, whereas this frequency decreases with increasing $\left|\gamma_{1}\right|$ and $g_{2}$.

To achieve a more complete description of tides worldwide, the tidal regime (TR), that is, its periodicity, was additionally included in this study. TR is calculated through the tidal form factor $(F)$, defined as the ratio of the amplitudes of the $\mathrm{O} 1$ and $\mathrm{K} 1$ constituents to those of the M2 and S2 constituents (Defant, 1961) (Equation 3):

$$
F=\frac{K_{1}+O_{1}}{M_{2}+S_{2}} .
$$

$F$ lower than 0.25 defines semidiurnal tidal regimes $(S) ; F$ between 0.25 and 1.5 characterizes mixed semidiurnal tides (MS); $F$ between 1.5 and 3 is representative of mixed diurnal tides (MD), and $F$ higher than 3 reflects diurnal tidal characters (D). Figure 4 shows the worldwide distributions of the tidal form factor (F) and their associated tidal regimes (TRs). From a comparison between Figures 3 and 4, the existence of a relationship between $F$ and $\gamma_{1}-g_{2}$ can be detected. Previous studies, such as those conducted by Blanton et al. (2002); Byun and Cho (2006); Hoitink et al. (2003), revealed asymmetries arising from some particular combinations of tidal constituents with specific tidal regimes, and Song et al. (2011) found a relationship between the tidal asymmetry $\left(\gamma_{1}\right)$ generated in the open ocean and $F$.

\subsection{Clustering}

The K-means algorithm was applied to $\gamma_{1}, g_{2}$, and TR to classify the tides. Due to the relationship among these three variables, joint clustering was performed. The K-means algorithm divides the starting data set into a given number of subsets. Each subset is represented by a centroid or prototype and consists of the data that are best represented by this prototype (Hastie et al., 2001). In this study, K-means was initialized with the maximum dissimilarity algorithm (Camus et al., 2011), and the parameters to be clustered were weighted according to the area that each triplet represents, $\left(1 / 30^{\circ}\right)^{2}$ or $\left(1 / 6^{\circ}\right)^{2}$. Once the centroids were found, the closest $\gamma_{1}, g_{2}$, and TR values of the original data set and their associated standardized PDF were selected. 
(a)
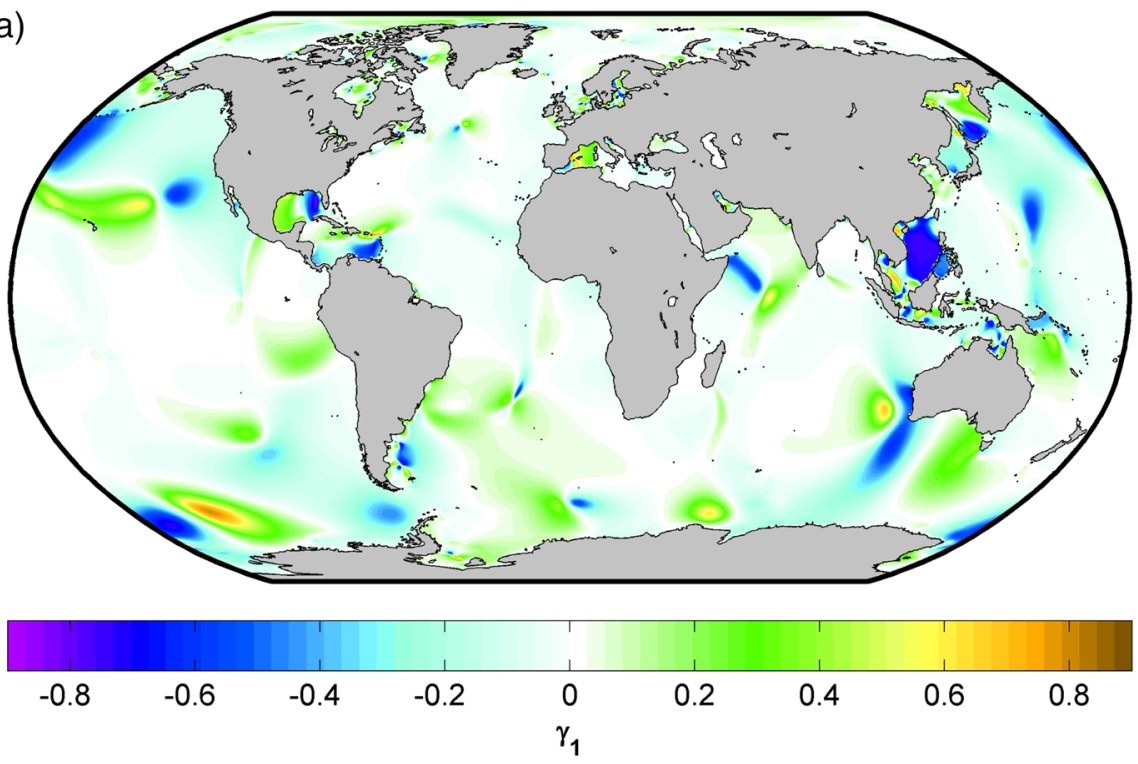

(b)
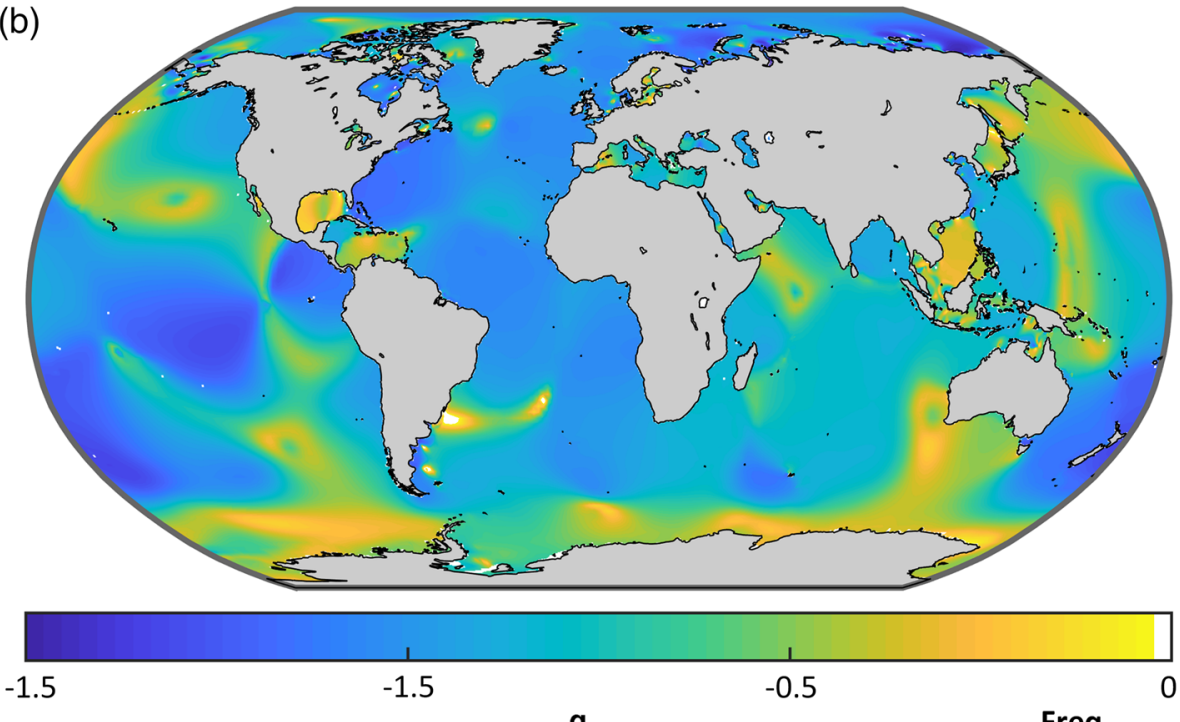

(c)

$g_{2}$

Freq.
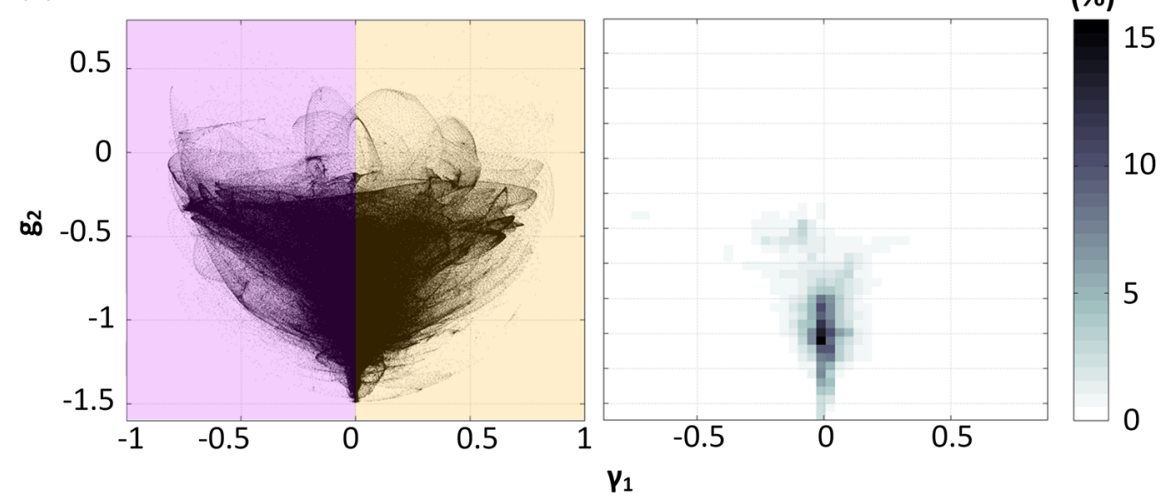

Figure 3. Statistical properties of the tidal elevation time derivative $(d \eta / d t)$ around the world: (a) skewness $\left(\gamma_{1}\right),($ b) excess kurtosis $\left(g_{2}\right)$, and (c) a scatter plot of $\gamma_{1}-g_{2}$ and the PDF frequency. 

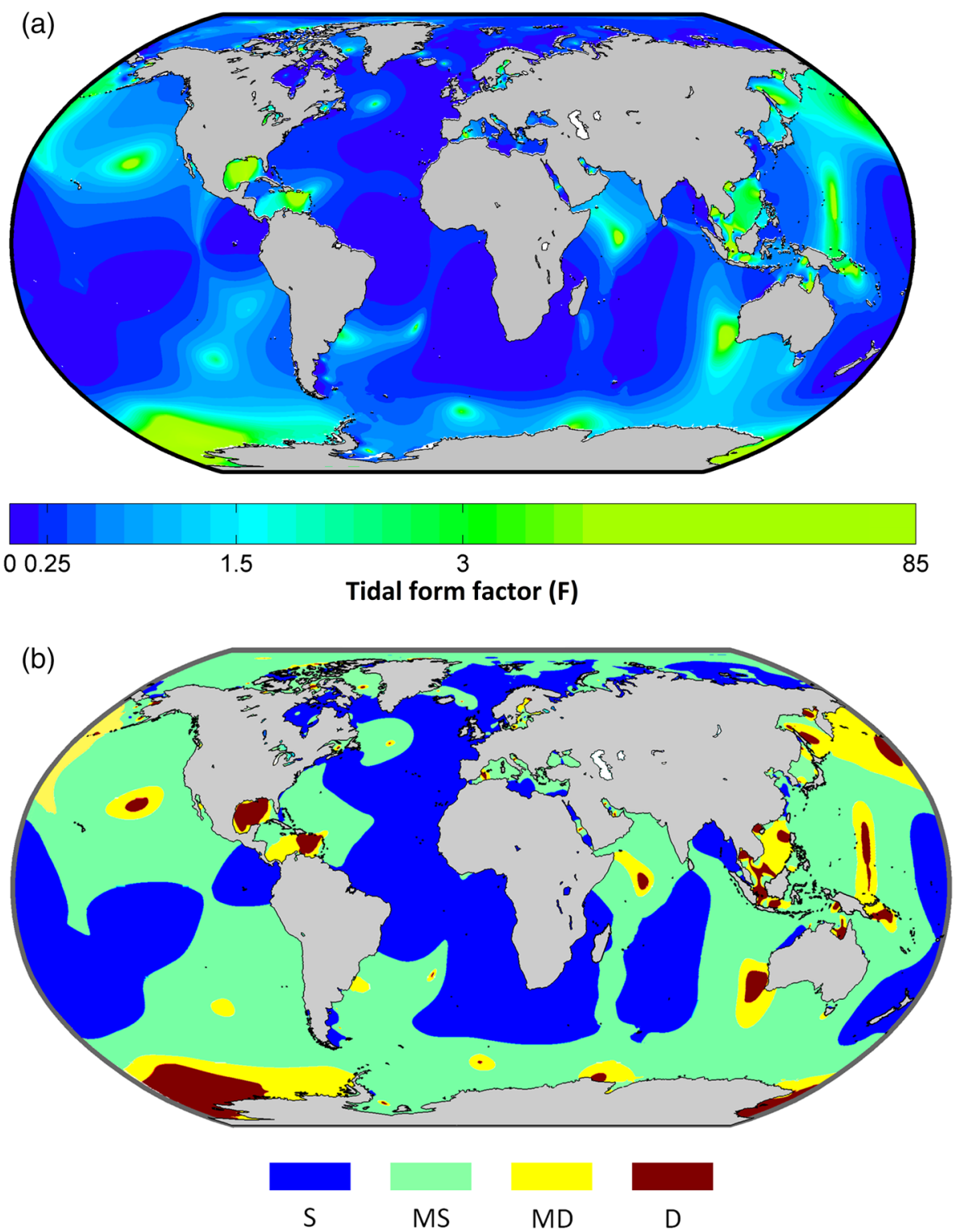

Figure 4. Global characterization of tidal periodicity: (a) tidal form factor $(F)$ and (b) tidal regimes (TRs) (semidiurnal, S; mixed semidiurnal, MS; mixed diurnal, MD; and diurnal, D).

To find the optimum number of clusters $(\mathrm{N})$ that best describes the ATtypes worldwide, K-means was preliminarily tested for different $\mathrm{N}$ values ranging between 2 and 98. A comparison between the original tide series and the synthetic time series reconstructed with the clusters derived from these classifications was performed using the efficiency coefficient (CE). CE was selected because it is the best objective function for reflecting the overall adjustment of a clustering output (Bárcena et al., 2015). CE is a normalized statistic developed by Nash and Sutcliffe (1970) that determines the relative magnitude of the residual variance (noise) and therefore reflects the accuracy with which the centroids estimate the original data (Equation 4):

$$
C E=\frac{\sum_{1}^{n}\left(O_{i}-C_{i}\right)^{2}}{\sum_{1}^{n}\left(O_{i}-\bar{O}\right)^{2}},
$$

where $O_{i}$ is the $i$-data $\left(\gamma_{1}, g_{2}\right.$, or TR) of the original series, $C_{i}$ is the $i$-data $\left(\gamma_{1}, g_{2}\right.$, or TR) of the representative centroid and $n$ is the number of nodes where the tide is evaluated. CE ranges between $-\infty$ and 1.0. The level of agreement between two series is valued as excellent if $\mathrm{CE}$ is higher than 0.8 , convenient if $\mathrm{CE}$ ranges between 0.6 and 0.8 , poor if $\mathrm{CE}$ is lower than 0.5 and unacceptable if $\mathrm{CE}$ is lower than 0 . Figure $5 \mathrm{a}$ 
(a)

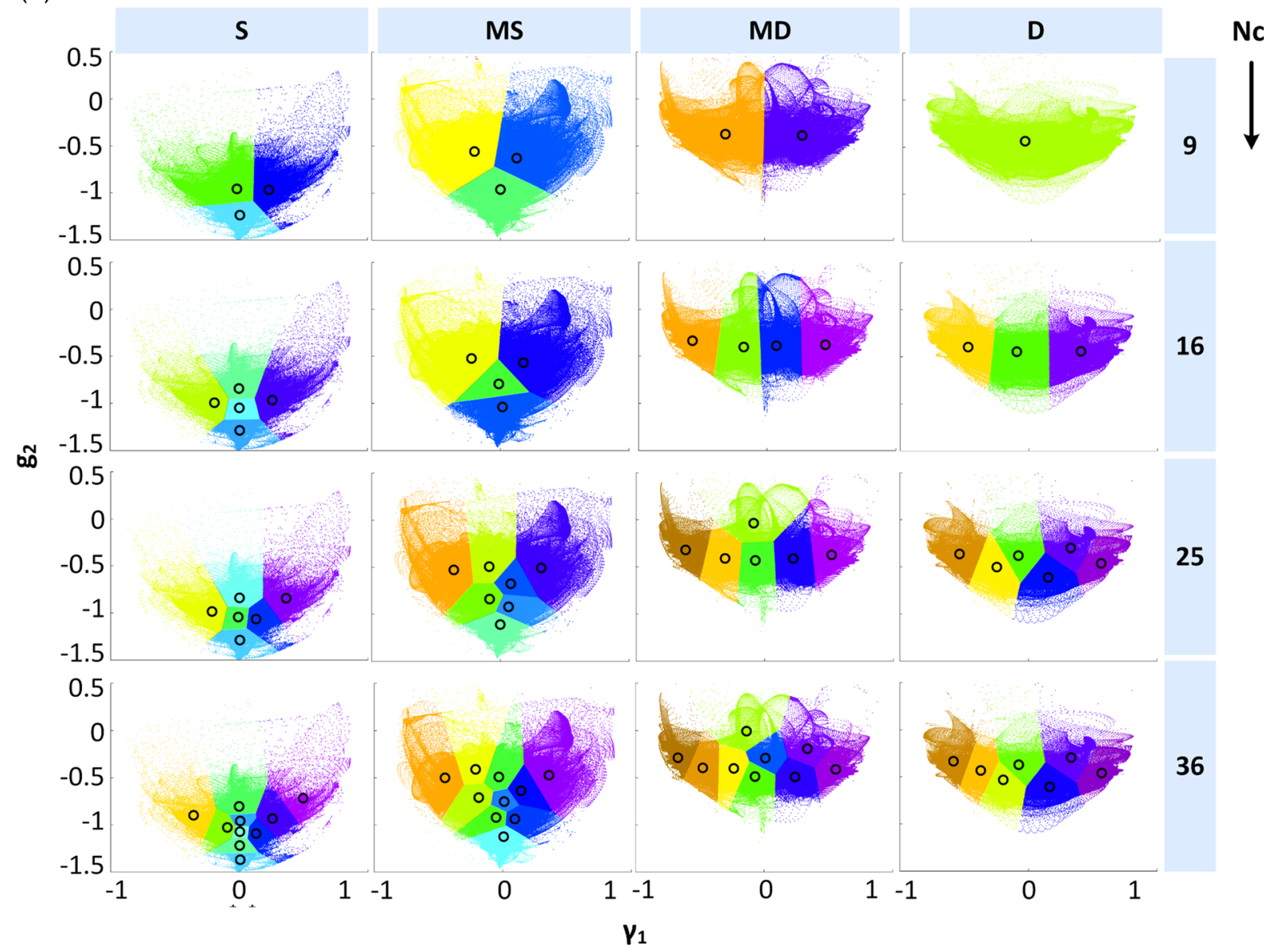

(b)

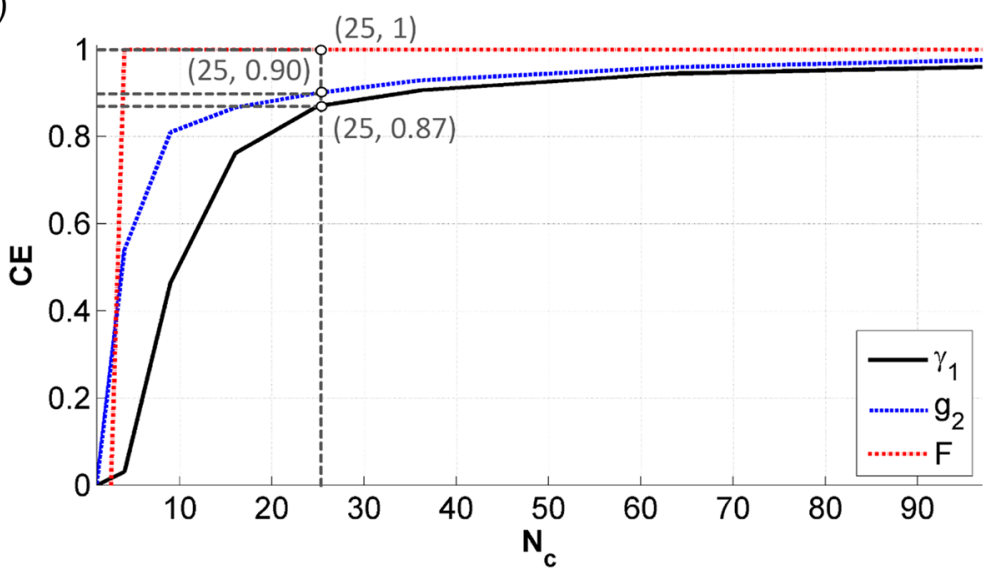

Figure 5. Representativity of the number of clusters $(N)$ : (a) scatter plots of $\gamma_{1}-g_{2}$ associated with different TR from TPXO9-atlas (color dots) and from the clustering (dots inside the black circles) for different $N$ and (b) efficiency coefficient (CE) of $\gamma_{1} / g_{2} / \mathrm{TR}$.

shows the scatter plots of $\gamma_{1}-g_{2}$ associated with each TR from TPXO9-atlas (color dots) and from the clustering (dots inside the black circles) for $\mathrm{N}$ equal to $9,16,25$, and 36. An increasing trend is observed for the original representativeness with the number of clusters. However, in the case of 36 clusters, centroids begin to be similar for the most frequent distributions (symmetric with small kurtosis), reducing the improvement in representativeness. $N$ equal to 25 was determined to be adequate because CE exceeds 0.8 for the three analyzed parameters $\left(\gamma_{1}, g_{2}\right.$, TR) and because the improvements are no longer significant for higher $N$ values (Figure $5 b$ ). 
(a)
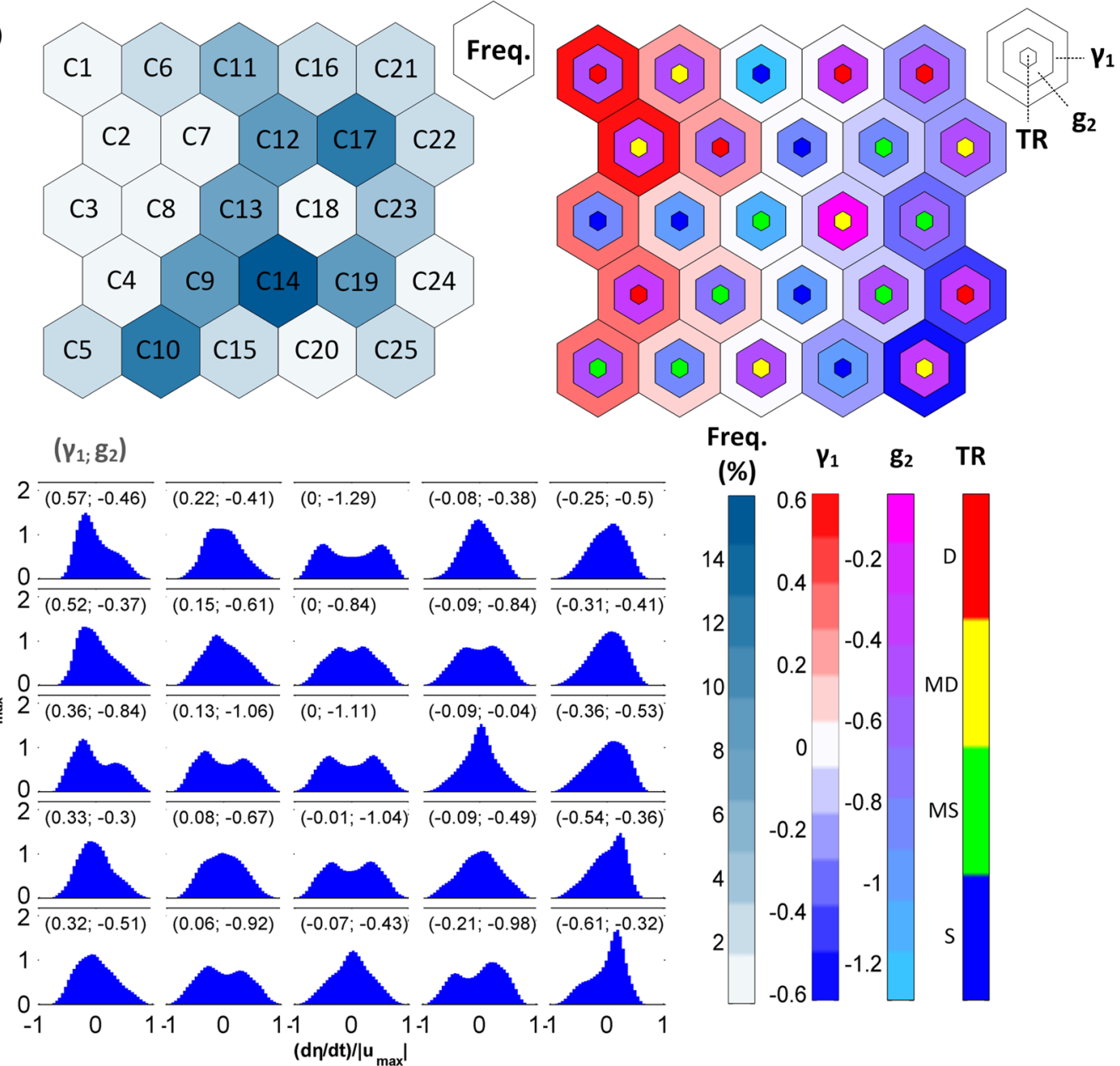

(b)

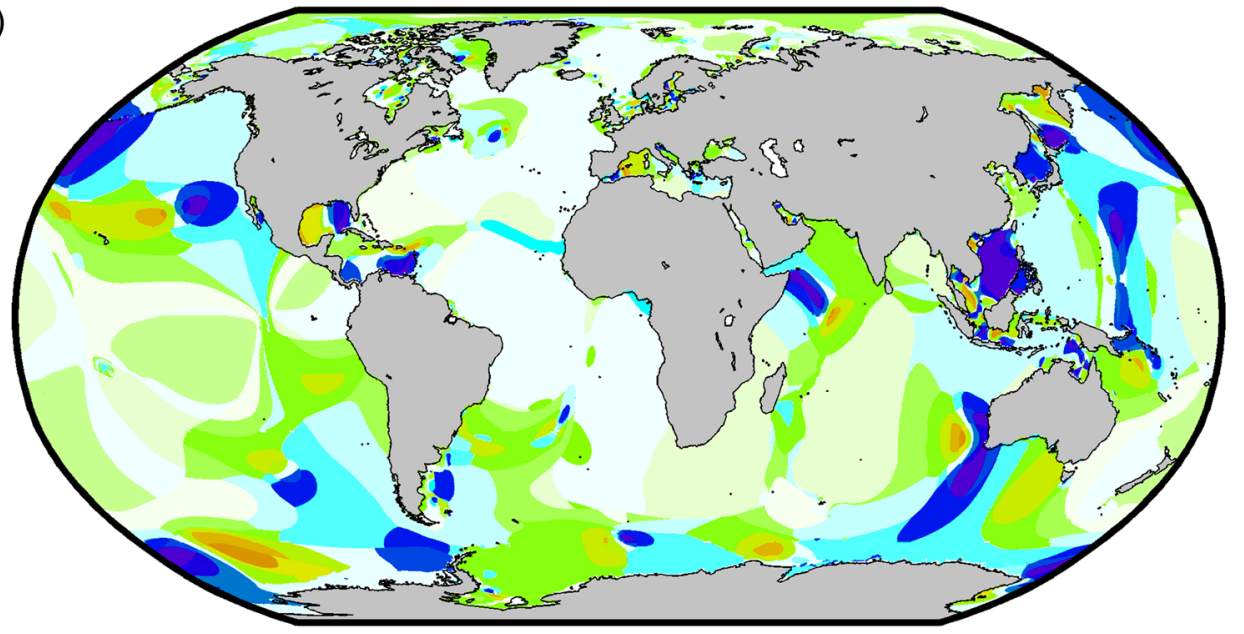

$c_{i}$

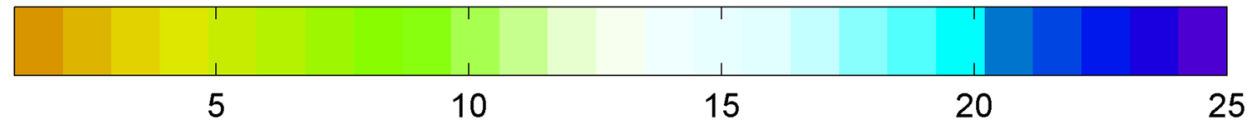

Figure 6. Global ATtypes from clustering: (a) statistics of the centroids $\left(C_{i}\right.$; Freq: frequency, $\gamma_{1}$ : skewness, $g_{2}$ : kurtosis, TR: tidal regime, PDF: probability density function) and (b) worldwide distribution of $C_{i}$. 


\subsection{ATtypes and contribution of combinations of tidal constituents}

Figure 6a shows the centroids $\left(C_{i}\right)$ from clustering sorted from the highest to the lowest value of $\gamma_{1}$. Each $C_{i}$ is defined in terms of the shape of its PDF of $d \eta / d t$ (i.e., its $\gamma_{1}$ and $g_{2}$ coefficients) and its tidal regime (S, MS, $\mathrm{MD}$, and $\mathrm{D}$ ) and represents an astronomical tide type (ATtype). Figure 6b shows the geographical distribution of the 25 identified ATtypes.

The results indicate that symmetric tides $\left(\left|\gamma_{1}\right|<0.1\right.$; from C9 to C19) dominate $85.3 \%$ of the world's open ocean, as well as $77.4 \%$ of all coastal areas. Indeed, symmetric tides correspond mainly to the mixed semidiurnal regime (approximately $60 \%$ of symmetric tides for the open ocean and coastal areas) and semidiurnal regime (approximately 36\% and 30\% of symmetric tides for the open ocean and coastal areas, respectively). A significant part of the Atlantic Ocean, including the East Coast of the United States, the western coast of Spain, and large proportions of the Brazilian and African coasts, exhibits these ATtypes (light-colored areas in Figure 6b). Conversely, 14 ATtypes show a clear asymmetric component $\left(\left|\gamma_{1}\right|>0.1\right)$, where the greatest asymmetries $\left(\left|\gamma_{1}\right|>0.5\right)$ occur in the diurnal and mixed diurnal regimes (i.e., C1, C2, C24, and C25). On the one hand, positive asymmetries (from $\mathrm{C} 1$ to $\mathrm{C} 8$ ) are found in $6.5 \%$ of the open ocean, and they make up $11.3 \%$ of the coastal areas throughout the world. The western Gulf of Mexico, the northern Caribbean Sea, the Mediterranean coast of France, part of the Spanish coast, and the south coast of Australia are good examples of these ATtypes (warm-colored areas in Figure 6b). The estuaries located in these coastal areas display flood dominance in their mouth, but this dominance can be affected or modified as a result of the estuarine morphology as the tide propagates into them. On the other hand, negative asymmetries (from C20 to C25) cover $8.2 \%$ of the open ocean and $11.3 \%$ of all coastal areas. The southern Caribbean Sea, the north coast of Greenland, the South China Sea, and the west coast of Australia are clear examples of areas with negative tidal asymmetries, and the estuaries hosted within these areas exhibit ebb dominance in their outermost zone (cold-colored areas in Figure 6b).

Moreover, the main tidal constituents that contribute to the total asymmetry in each ATtype were identified. To this end, the method proposed by Song et al. (2011) was applied to to 25 clusters, derived from TPXO9atlas. At each of these clusters, the contributions $\left(\beta_{i}\right)$ to $\gamma_{1}$ of the different combinations (pairs or triplets) of tidal constituents that can influence the asymmetry were calculated, that is, the constituents for which the following frequency ratios $2 \omega_{1}=\omega_{2}$ or $\omega_{1}+\omega_{2}=\omega_{3}$ are met. Finally, the subset of tidal constituents that best explains the $\gamma_{1}-g_{2}$ pair was selected from those constituents.

Figure $7 \mathrm{a}$ shows the pairs and triplets of tidal constituents that contribute to tidal asymmetry as well as the value of each contribution $\left(\beta_{i}\right)$, expressed as a percentage, to each ATtype $\left(C_{i}\right)$. Each $C_{i}$ on the $y$-axis is represented by a color associated with a tidal regime, namely, blue for S, green for MS, yellow for MD, and red for D. It is worth noting that there are combinations that contribute with the same orientation as the characteristic skewness $\left(\gamma_{1}\right)$ of each $C_{i}$ (warm-colored cells in Figure 7a), while others counteract $\gamma_{1}$ (cold-colored cells in Figure 7a). The sum of all contributions results in the representative $\gamma_{1}$. As the figure shows, the symmetric tides $\left(\left|\gamma_{1}\right|<0.1\right)$ have a greater number of combinations that contribute a similar percentage, although with different orientations, to the resulting skewness and that all contributions are balanced between them, thereby canceling out $\gamma_{1}$. Conversely, tides with a significant asymmetrical component $\left(\left|\gamma_{1}\right|>0.1\right)$ show a clear and large contribution. In general, the astronomical triplet $\mathrm{O} 1 / \mathrm{K} 1 / \mathrm{M} 2$ dominates the $\mathrm{D}, \mathrm{MD}$, and MS regimes, while the $\mathrm{P} 1 / \mathrm{K} 1 / \mathrm{S} 2$ and M2/M4 combinations play a secondary or tertiary role in the asymmetry. In the $S$ regime, the main contribution comes from M2/M4. Among the set of analyzed combinations, the subset of constituents that best explain the $\gamma_{1}-g_{2}$ pair was selected (framed in gray). This analysis indicates that a relatively small number of tidal constituents plays a role in the definition of $\gamma_{1}$; however, a greater number is necessary to characterize $g_{2}$. Figure $7 \mathrm{~b}$ shows the good agreement between the total skewness and excess kurtosis resulting from the classification $\left(\gamma_{1}-g_{2}\right)$ and the same statistics obtained from the main tidal constituents $\left(\gamma_{1}-g_{2}\right)$, with $R^{2}$ exceeding 0.9 in both cases.

Figure 8 shows the global distributions of the contributions $\left(\beta_{i}\right)$ of the main tidal constituents responsible for the asymmetry of each of the identified ATtypes. It is noticeable that the O1/K1/M2 and M2/M4 combinations have contributions with greater intensities. The contributions of $\mathrm{P} 1 / \mathrm{K} 1 / \mathrm{S} 2$ and $\mathrm{M} 2 / \mathrm{S} 2 / \mathrm{MS} 4$ are less significant by a factor ranging from 3 to 5 , and the contributions of $\mathrm{K} 1 / \mathrm{K} 2$, M2/N2/MN4, and Q1/K1/N2 are 
(a) $\mathrm{C1}$

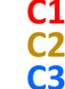

C3

C5

C6

C8

C9

C10

C11

C12

C13

C14

C15

C16
C17

C18

C19

C20

C21

C22

C24

C25

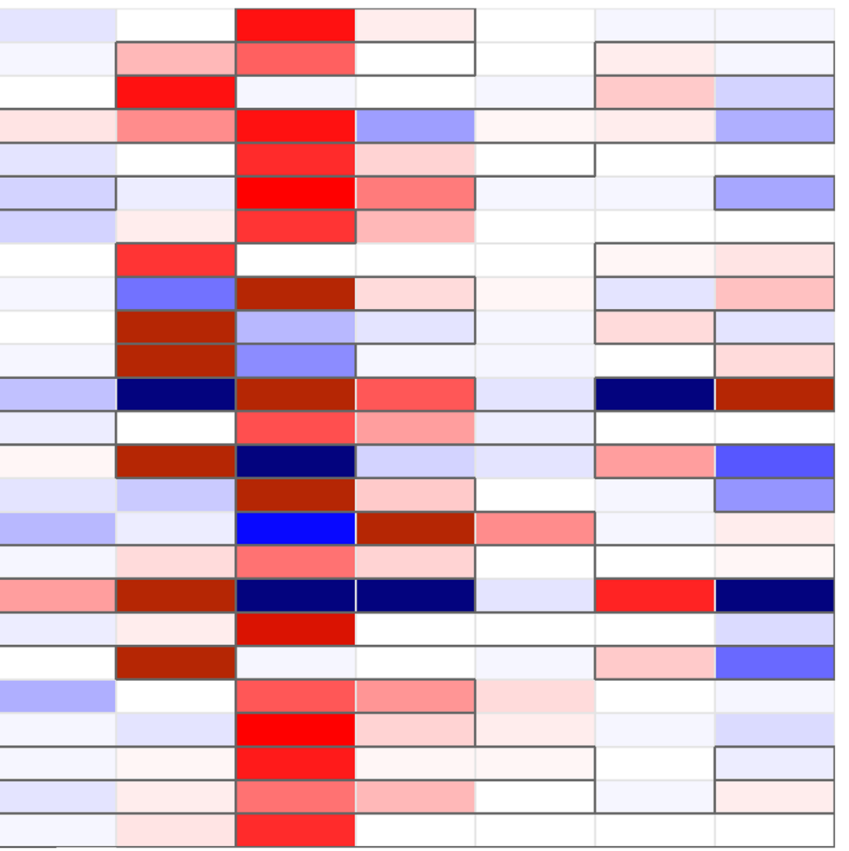

100

$-80$

60

$-40$

20

$0 \frac{\widehat{a}}{0^{2}}$

$-20$

$-40$

$-60$

$-80$

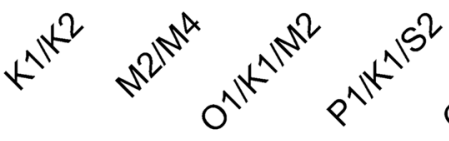

(b)

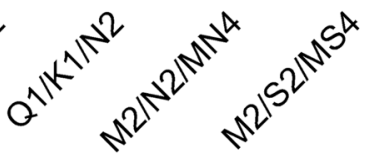

(c)
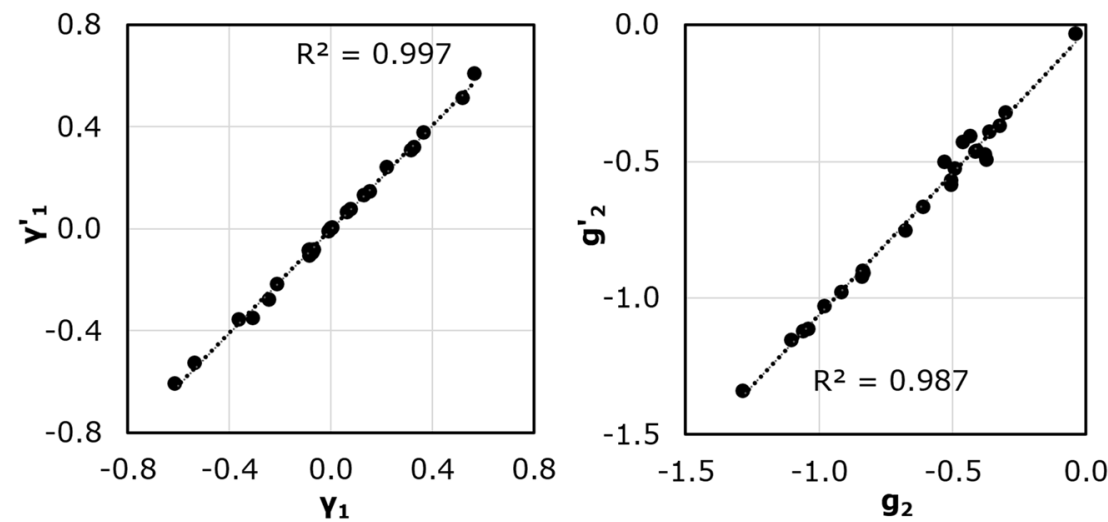

Figure 7. (a) Contributions $\left(\beta_{i}\right)$ of the combinations of tidal constituents to the skewness of the ATtypes ( $\left.C_{i}\right)$ (the greatest contributions that explain the $\gamma_{1}-g_{2}$ pair are framed in gray); (b) scatter plot of $\gamma_{1}$ (from clustering)- $\gamma_{1}$ (resulting from the main tidal constituents that explain the PDF shape); and (c) scatter plot of $g_{2}$ (from clustering) $-g_{2}$ (resulting from the main tidal constituents that explain the PDF shape). Each $C_{i}$ on the $y$-axis is represented by a color associated with a tidal regime, namely, blue for $\mathrm{S}$, green for MS, yellow for MD, and red for D.

characterized by a lower order of magnitude. The main contributions of O1/K1/M2 and M2/M4 were estimated to account for $95 \%$ and $5 \%$, respectively, of the tidal asymmetry in the open ocean. Indeed, the maps presented in Figure 8a ( $\beta_{O 1 / K 1 / M 2}$ from clustering), Figure $8 \mathrm{~h}$ ( $\sum \beta$ from clustering), and Figure 3a $\left(\gamma_{1}\right.$ from TPXO9-atlas) are very similar.

\section{Validation}

The classification results were validated with 757 selected tide gauge records from GESLA-2. To ensure the representativeness of the external tide, one record was selected per tide gauge located at a distance of less than $10 \mathrm{~km}$ from the nodes where the clustering outputs are available. On the one hand, the PDFs of the 
(a)

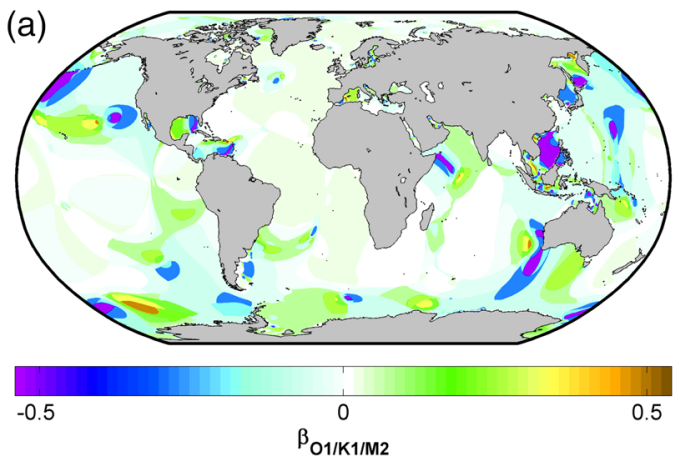

(c)
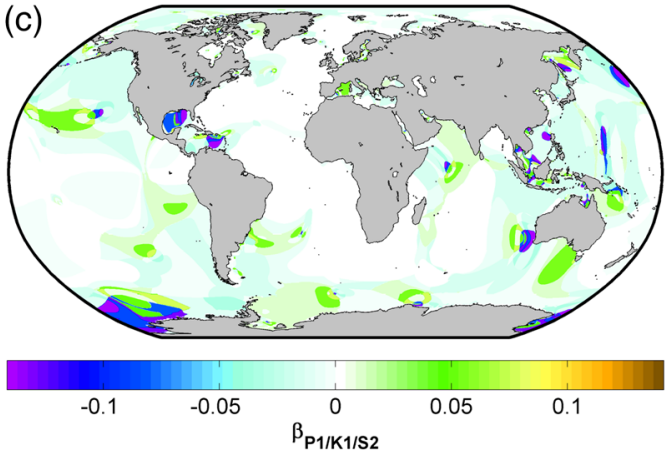

(e)

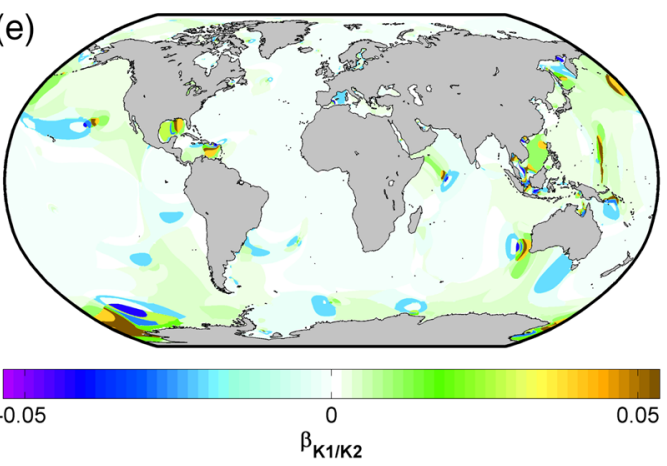

(g)

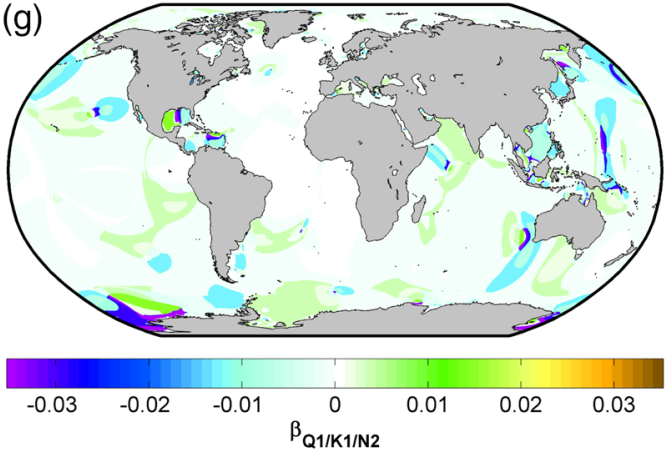

(b)

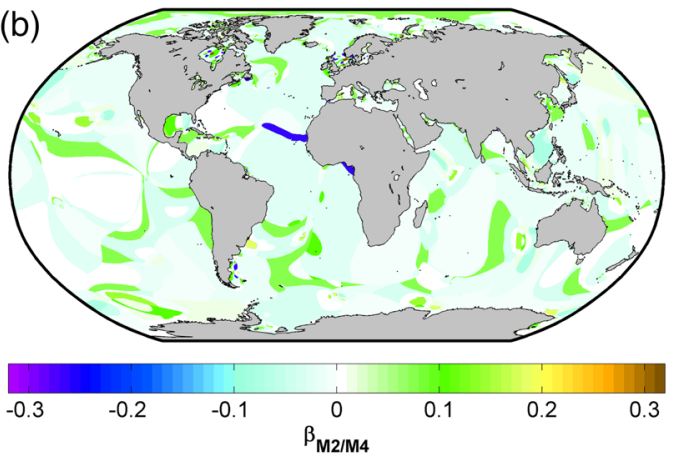

(d)

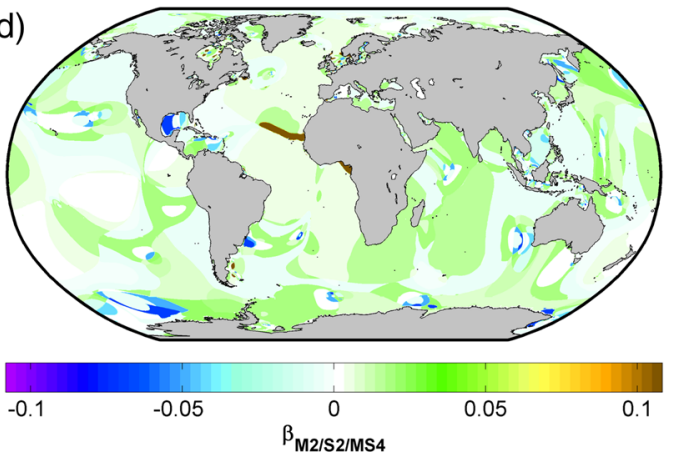

(f)

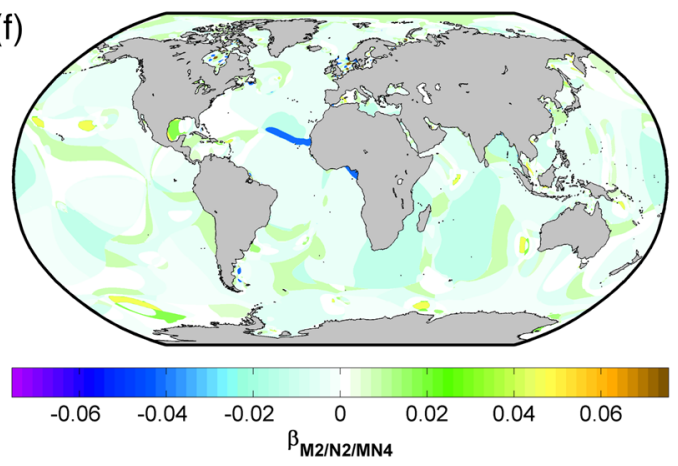

(h)

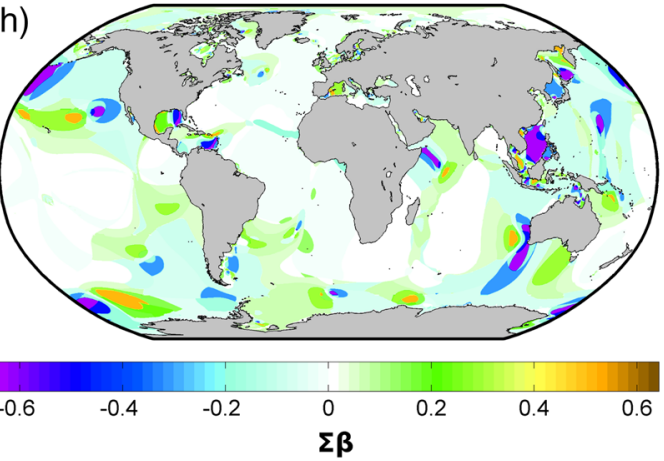

Figure 8. Global distributions of the contributions $\left(\beta_{i}\right)$ of the main tidal constituents responsible for the asymmetry of the ATtypes: (a) O1/K1/M2, (b) M2/M4, (c) P1/K1/S2, (d) M2/S2/MS4, (e) K1/K2, (f) M2/N2/MN4, (g) Q1/K1/N2, and (h) sum of all contributions $\left(\sum \beta\right)$. Note the differences in the color scales.

$d \eta / d t$ product of clustering were compared with those obtained from the tide gauge records by applying the CE statistic (Equation 4). Since PDFs depend on the analyzed time window and tide gauge records cover different time periods, harmonic analysis of each record was performed to then reconstruct the $d \eta / d t$ series over the same 19-year period. On the other hand, the degree of matching between the tidal regimes from both sources was evaluated. 
(a)

\begin{tabular}{|ccll}
\hline CE & & $\ddots$ & Poor \\
- & Unaceptable & $\bigcirc$ & Good \\
& Aceptable (-) & $\bullet$ & Excellent \\
\hline
\end{tabular}
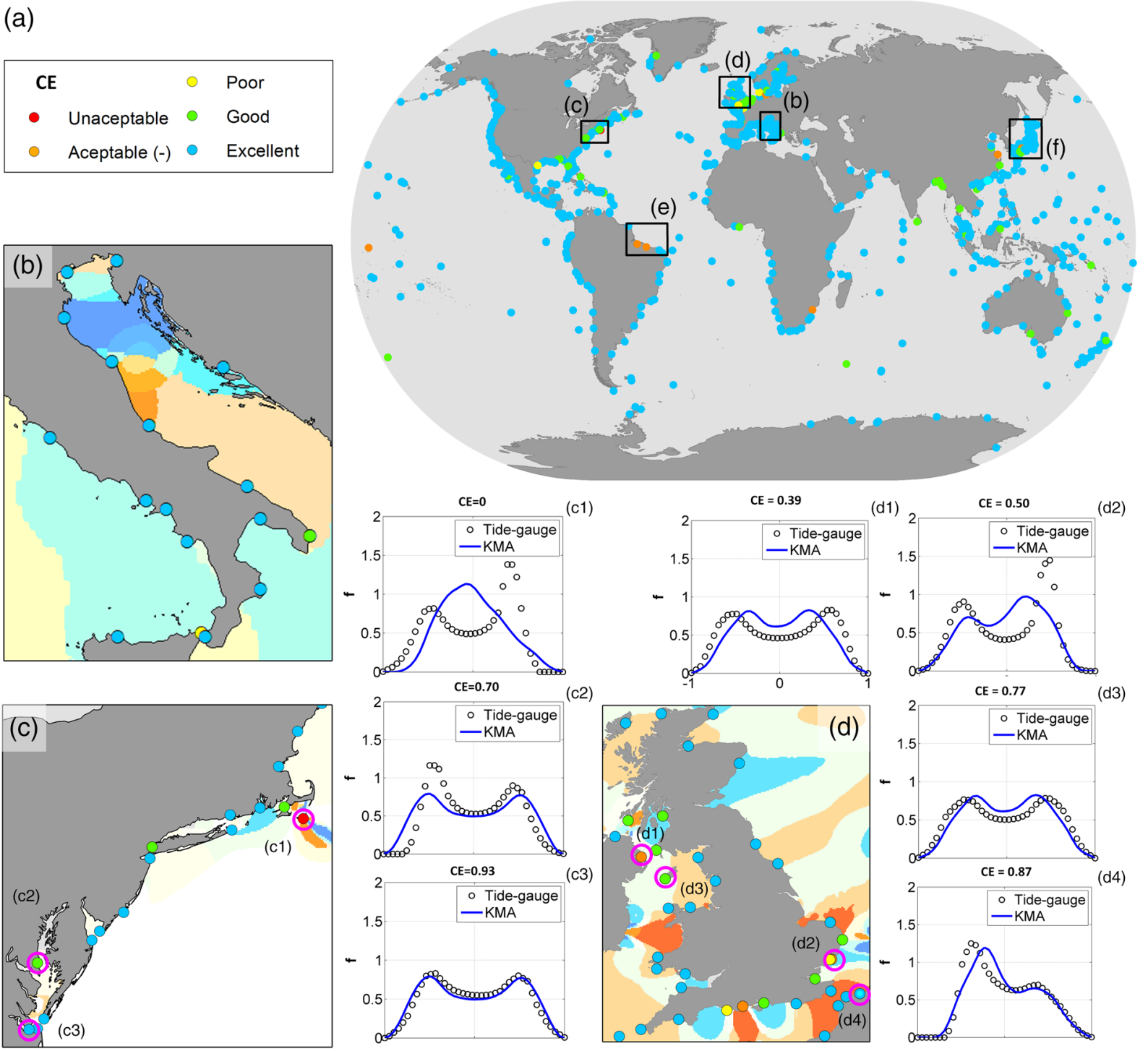

(c2)
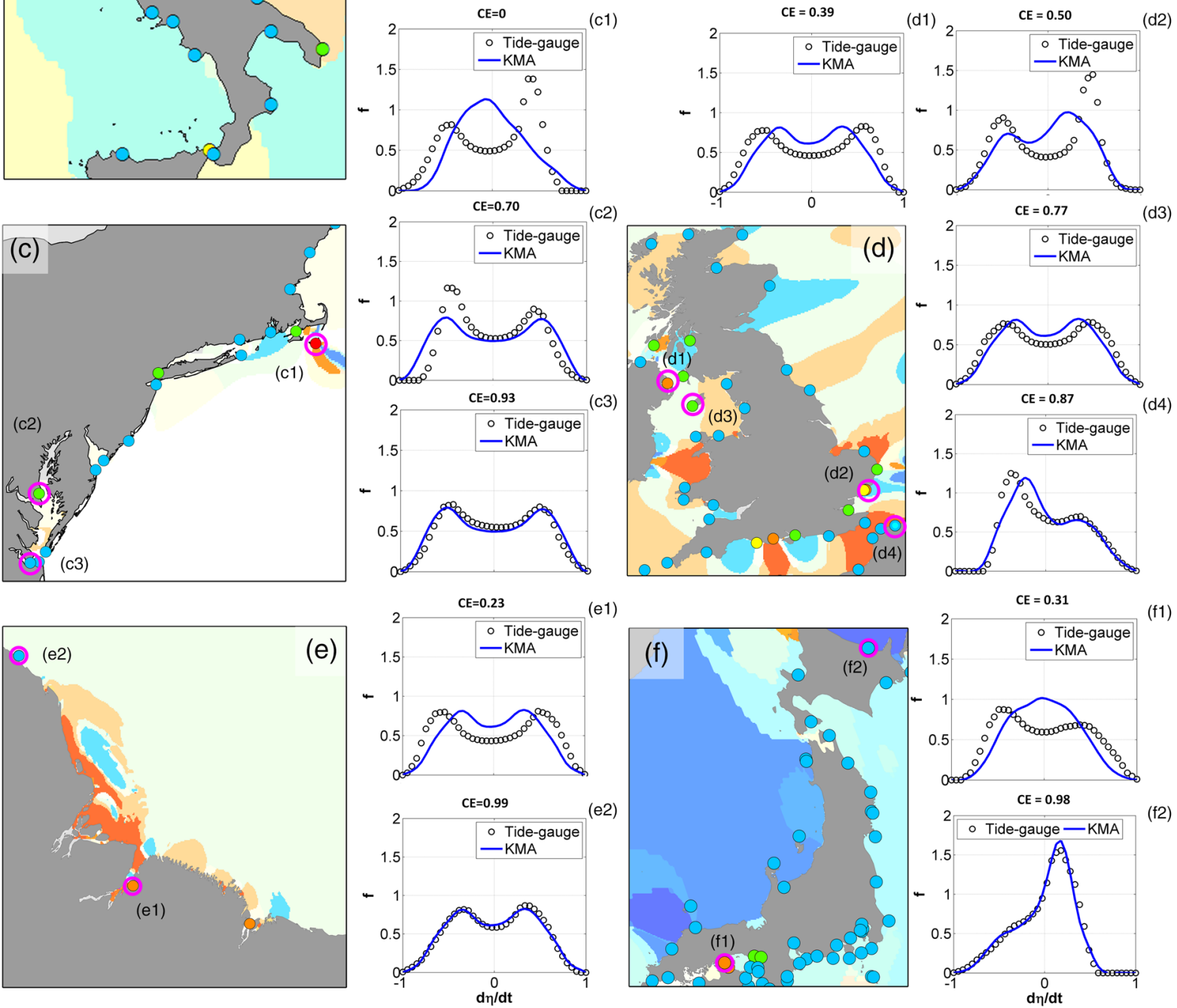

$C_{i}$

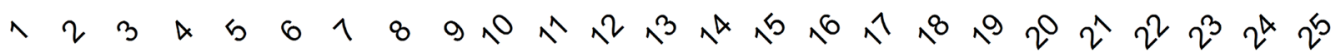

Figure 9. Efficiency coefficient (CE) between the PDFs from clustering and the PDFs from the tide gauge records worldwide (a) and in the following areas: the Adriatic Sea (b), the central East Coast of the USA (c), the coastlines of Ireland and the United Kingdom (d), the northern Brazilian coast (e), and the Japan coast (f). Some examples of PDFs that show different levels of agreement in these areas are labeled $\mathrm{c}_{i}, \mathrm{~d}_{i}, \mathrm{e}_{i}$, and $\mathrm{f}_{i}$. 
(a)
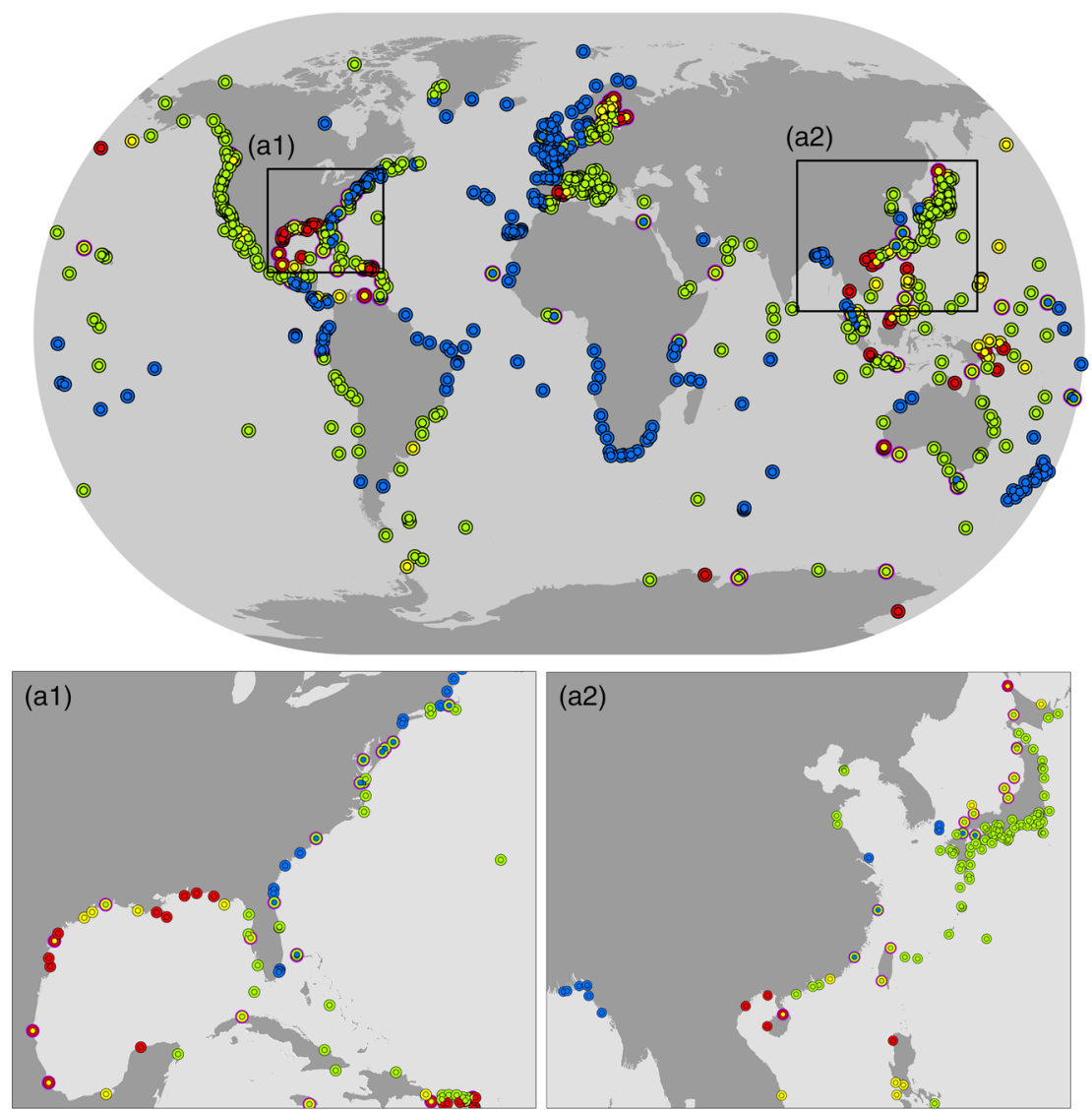

(b)
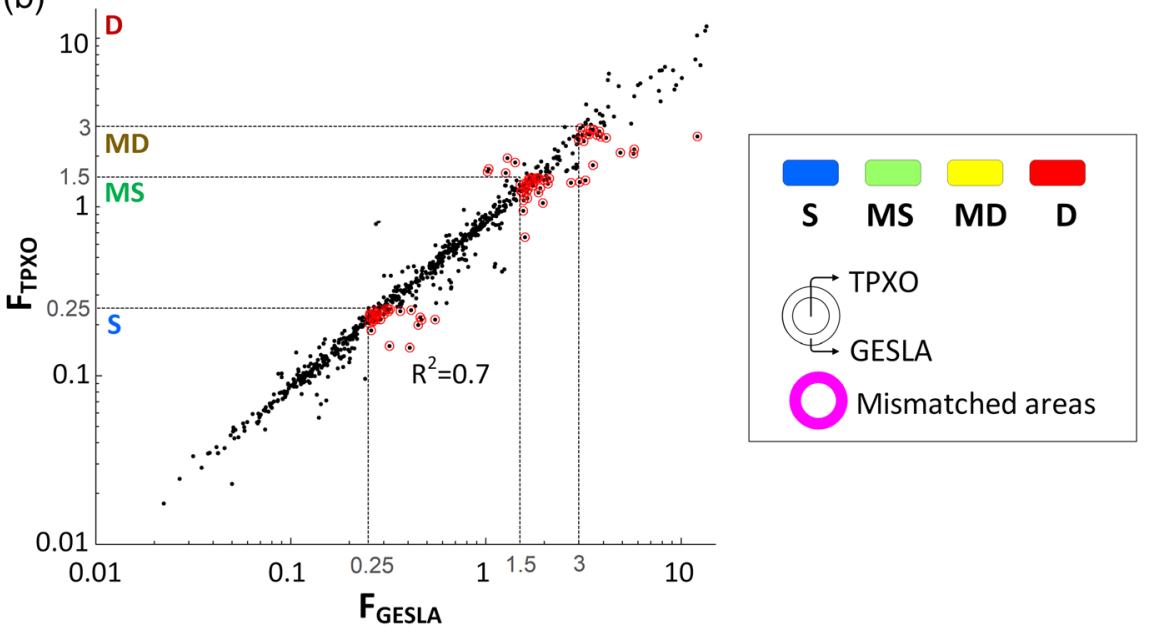

Figure 10. Matched/mismatched indicators between the tidal regimes (TR) from clustering and the tide gauge records worldwide (a) and in the following areas: the Gulf of Mexico and southeast coast of the United States (a1) and the Sea of Japan and East China Sea (a2); (b) scatter plot between the tidal form factor $(F)$ from tide gauges (GESLA-2) and from TPXO9-atlas (mismatched points are highlighted in red).

Regarding the comparison among the PDFs, Figure 9 shows the degree to which the outputs from clustering represent the tidal conditions recorded at the tide gauges. A total of 684 tide gauges are represented in blue, which is associated with an excellent characterization ( $\mathrm{CE}>0.8) ; 54$ tide gauges are shown in green, indicative of good agreement $(0.6<\mathrm{CE} \preccurlyeq 0.8)$; seven tide gauges are shown in yellow, which reflects poor representativeness $(0.5<\mathrm{CE} \preccurlyeq 0.6)$; 14 tide gauges show acceptable but worse than poor agreement $(0<\mathrm{CE} \leqslant 0.5)$ and are represented in orange; and finally, one tide gauge was represented in red, indicating unacceptable 

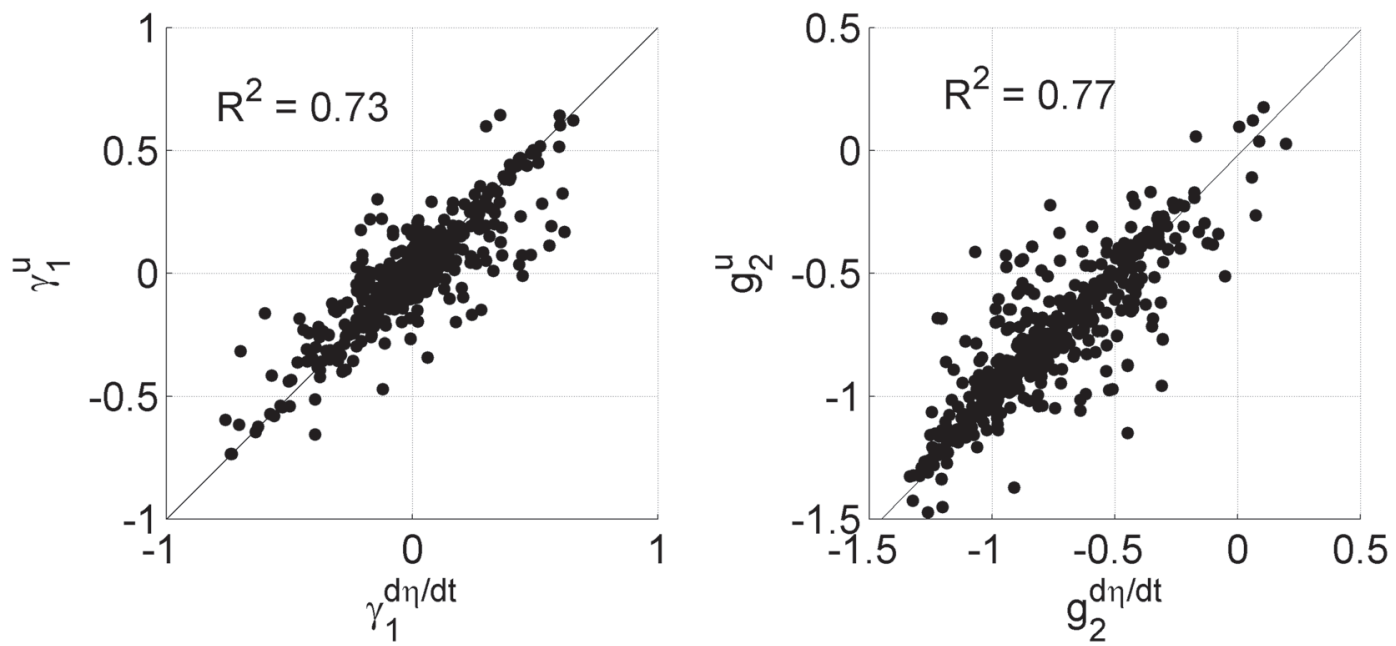

Figure 11. Relationships between the statistical parameters $\gamma_{1}$ and $g_{2}$ for $d \eta / d t$ and $u$ (tidal currents in the average direction of tidal propagation).

representativeness (CE $\preccurlyeq 0)$. Hence, 97\% of the clustered PDFs characterize the PDFs of the world's coastal areas well or very well, and only $3 \%$ exhibit poor or unacceptable representativeness. As an example of the classification ability to characterize tides even in complex tidal areas, Figure $9 \mathrm{~b}$ shows the Adriatic Sea. In this region, where up to 10 different ATtypes with $\gamma_{1}$ ranging from -0.36 to 0.32 are observed, the validation verifies the classification results with an excellent degree.

The main reason for the disagreement between the clustered PDFs and those obtained from the tide gauge records is not related to the type of PDF but rather to the geometric complexity of the area surrounding the represented node. Figure 9 shows the classification represents different types of distributions with a high level of agreement, such as symmetric bimodal distributions (e.g., c3 $\mathrm{CE}=0.93$ and e2 $\mathrm{CE}=0.99$ ), asymmetric bimodal distributions (e.g., $\mathrm{d} 4 \mathrm{CE}=0.87$ ) and asymmetric unimodal distributions (e.g., f2 $\mathrm{CE}=0.98$ ). Concerning this issue, areas $\mathrm{c}, \mathrm{d}$, e, and $\mathrm{f}$ in Figure 9 represent the main problem areas with regard to the representativeness. Area c corresponds to the East Coast of the United States ranging from Chesapeake Bay to the vicinity of Portland (Maine, USA). This area contains a unique tide gauge that the clustering classifies with an unacceptable level $(\mathrm{cl} \mathrm{CE}=0)$. The reason for this result is the location of the tide gauge in a shallow and narrow area on the NW coast of Nantucket Island (USA), where different types of tides converge ( $\mathrm{C} 5, \mathrm{C} 13$, and $\mathrm{C} 23$ centroids with $\gamma_{1}$ values equal to $0.32,0$, and -0.36 , respectively). Area d corresponds to the coastlines of Ireland and the United Kingdom, where tide gauges with low levels of concordance are observed (e.g., d1 CE $=0.39$ and d2 $-\mathrm{CE}=0.50$ ). Due to the complex geometry of the Northern Europe coastlines (Irish Sea, the English Channel, etc.) and the effect of this geometry on the tides, almost half (45.5\%) of the tide gauges located in these areas show CE values lower than 0.6. In area e, located along the northern Brazilian coast, two tide gauges are inadequately characterized due to their locations in very shallow-water areas that local TPXO models fail to describe (e.g., e1 CE $=0.23$ ). In area " $\mathrm{f}$ " (Japan), there are a few points with a low classification representativeness since they are embedded in narrow areas (e.g., f1 $\mathrm{CE}=0.31$ ). Despite all of the abovementioned factors, it can be seen in Figure 9 that even in these problematic areas, the number of nodes with a good or excellent level of agreement predominates over the number of nodes with poor or worse concordance.

Figure 10 shows the tidal regimes (TRs: $\mathrm{S}$ in blue, MS in green, MD in yellow, and D in red) obtained from the selected tide gauges (outer ring) and those according to the performed classification (inner circle). In addition, the mismatched points are highlighted with a violet ring. The TRs coincide in $87 \%$ of the locations compared, while there is one regime difference in the remaining 13\%. The main areas in which these mismatches are concentrated are the Gulf of Mexico and the East Coast of the United States (area a1 in Figure 10), and the west coast of Japan (area "a2"). Figure 10b shows a scatter plot between the tidal form factors $(F)$ obtained from the tide gauge records and those obtained from TPXO9-atlas, where the 
mismatched points are highlighted with a red circle. This figure verifies that most of the points where the clustered TRs do not coincide with the recorded TRs are in the transition areas between two regimes.

As mentioned in section 1 (Introduction), the $d \eta / d t$ variable was chosen for this study instead of the tidal current $(u)$ because of its validation possibilities and since long tidal current records for the entire globe are scarce. To check the similarity between these two variables in coastal areas, the $\gamma_{1}$ and $g_{2}$ values of the 19-year time series of both the $d \eta / d t$ and $u$ in the average direction of tidal propagation (both variables reconstructed from TPXO9-atlas) were compared at the validation points. Figure 11 shows the correlations between the two statistical descriptors for both variables ( $R^{2}$ is equal to 0.73 and 0.77 for $\gamma_{1}$ and $g_{2}$, respectively); therefore, the suitability of selecting $d \eta / d t$ to classify ocean tides in the world's coastal areas is verified.

The above analysis shows that a very good tidal characterization dominates the global map, even in the most problematic areas. Hence, it can be concluded that the developed tidal classification represents the astronomical tide conditions throughout the world's coastal areas with high reliability.

\section{Discussion}

It has been effectively demonstrated that tidal asymmetry evolves over relatively short distances in coastal, estuarine, and river environments and influences the behaviors of these areas (Hoitink et al., 2006). The characterization of tidal asymmetry in open oceans is a very relevant aspect for the study of estuarine processes since tidal asymmetry constitutes the boundary condition that influences the propagation of tidal waves throughout an estuary and, consequently, the transport processes that occur within the estuary, as well as estuarine-ocean exchanges (Ranasinghe \& Pattiaratchi, 2000). In this study, the most recent version of the TPXO Global Tidal Solutions (TPXO9-atlas), statistical methods (PDFs), and clustering and harmonic approaches were used to effectively describe the tidal asymmetry in coastal areas before the propagation of tides into estuaries. Thereby, results of this study facilitate research from complementary statistical and harmonic perspectives (Guo et al., 2019) and simplify the study of the evolution of tidal asymmetry when a tide propagates through any estuary in the world by analyzing only the responsible constituents.

The high quality of the information provided by the global classification of tides was demonstrated with the excellent agreement obtained in 97\% of the nodes in which the PDFs were compared (Figure 9) and in $87 \%$ of the nodes in which the tidal regimes were checked (Figure 10), what also confirms the accuracy of the new TPXO9-atlas solution to characterize the coastal tides. The common denominator of the few nodes in which the distributions are not well characterized is their location, that is, areas exhibiting a complex geometry (areas too narrow or having significant depth changes, such as the interiors of estuaries) that even the local models of TPXO9-atlas do not describe with adequate precision. These features have significant local effects on tidal conditions, since they can induce overtides and compound tides which influence the resulting asymmetry and cannot be adequately reproduced by the TPXO tidal models or generate areas where different tidal typologies converge. Therefore, to characterize the tide anywhere in the world, it is recommended to use those nodes which are far enough from these complex areas and propagate the tide from well characterized areas if necessary.

As shown in section 3 (Results), symmetric tides cover $77.4 \%$ of the world's coastal areas, and most of these tides correspond to the mixed semidiurnal regime $(60 \%)$, followed by the semidiurnal regime $(30 \%)$ (Figure 6). The tidal asymmetries in the estuaries located in these areas depend exclusively on overtides and compound tides generated during inland propagation without being conditioned by external tidal features. On the other hand, although asymmetric tides constitute a smaller percentage, identifying them correctly is essential for describing any estuarine process dependent on tidal hydrodynamics since the identification of asymmetric tides can have very different consequences from the predictions derived from an assumption of tidal symmetry. The most asymmetric tides, both positive and negative, are concentrated in relatively adjacent areas of the world and mainly correspond to diurnal and mixed diurnal regimes (Figure 6). The reason for these maximum tidal asymmetries in the open ocean is fundamentally the interactions among the main tidal constituents. The astronomical triplet $\mathrm{O} 1 / \mathrm{K} 1 / \mathrm{M} 2$ dominates in the $\mathrm{D}$, MD, and MS regimes, followed by the $\mathrm{P} 1 / \mathrm{K} 1 / \mathrm{S} 2$ and M2/M4 combinations, whereas the main contribution to the $\mathrm{S}$ regime comes from the M2/M4 constituents (Figure 7a); these results are consistent with the findings of Song et al. (2011). Positive asymmetries characterize $11.3 \%$ of the world's coastal areas and influence the 
behaviors of estuaries dominated by tides that exhibit flood dominance in their mouths. A good example of this type of environment is the Dee estuary (United Kingdom), which shows an overall flood dominance that is likely induced by positively asymmetric ocean tides, which explains the known historical changes in the estuarine morphology (large-scale accretion over the last 2 centuries) (Moore et al., 2009). Negative asymmetries are also present in the same percentage as positive asymmetries (11.3\%) and can influence estuaries with external ebb dominance. Ranasinghe and Pattiaratchi (2000) studied three West Australian inlets whose mouths are dominated by ocean tides with long-term negative asymmetry. The authors showed that, despite the alternation of ebb- and flood-dominated periods, over a period of 1 year (to investigate the long-term effect), the net transport of sediment through the entrances of these systems was directed towards the sea. Nidzieko (2010) investigated three California estuaries with negative tidal asymmetries imposed in their mouths and demonstrated that such asymmetries increase or decrease (according to the estuarine morphology) as the tide propagates landward and therefore affects several internal processes. Similarly, Ferrarin et al. (2015) and Finotello et al. (2019) point out that the inlet region and the main channels of Venice lagoon were dominated by the negative tidal asymmetry of the North Adriatic Sea. Ferrarin et al. (2015) obtained the annual value of $\gamma_{1}$ in the period 1976-2014 with the data of a tide gauge station located $15 \mathrm{~km}$ offshore from the Venice lagoon inlets and verified that $\gamma_{1}$ oscillated around an average value of -0.09 , coinciding with the results of the classification carried out in this study. As these authors concluded, although tidal asymmetry develops according to the estuarine morphology as the tide propagates, the asymmetry imposed at the mouth of the estuary must first be overcome.

\section{Conclusions}

This research addresses the study of tidal asymmetry on a global scale, based on a statistical approach adequate when asymmetry results from the interaction among multiple tidal constituents. Astronomical tide has been classified by applying a clustering K-means technique to the TPXO9-atlas solution, a complete (15 tidal constituents) barotropic tidal solution with a high spatial resolution $\left(1 / 30^{\circ}\right)$ to describe the tidal conditions in the vicinity of coastal areas. Accordingly, this study increased the knowledge available in the current state of the art about the long-term tidal distribution on a global scale.

Twenty-five astronomical tide types were identified (through PDFs of the tidal elevation time derivatives), and the main tidal constituents associated with each tide type were estimated. The classification was validated by comparing the outputs with the data from 757 tide gauges strategically distributed to cover the world's coastal areas. The results showed that both the open ocean and the coastal areas are dominated by symmetric tides ( $85.3 \%$ and $77.4 \%$, respectively); negative asymmetries characterize $8.2 \%$ of open oceans and $11.3 \%$ of coastal areas; and positive asymmetries cover $6.5 \%$ of open oceans and $11.3 \%$ of coastal areas. In general, the astronomical triplet $\mathrm{O} 1 / \mathrm{K} 1 / \mathrm{M} 2$ controls the tidal asymmetries in the diurnal, mixed diurnal, and mixed semidiurnal regimes, whereas the M2/M4 pair of constituents is the combination that stands out for most semidiurnal regimes.

The developed classification represents a guiding framework regarding the types of astronomical tide according to their asymmetry (orientation and degree) and periodicity on a worldwide scale. This framework can be used as a reference for further research on the transport of substances (e.g., sediments, nutrients, plastics, oil spills, and chemicals) in estuaries, as the asymmetry imposed at the mouth of an estuary may influence most internal transport processes.

\section{Data Availability Statement}

All the data resulting from this study have been obtained by statistical analysis of preexisting databases available online, namely, TPXO9-atlas and GESLA-2. TPXO9-atlas barotropic tidal solution are provided by the Oregon State University (USA) and is available online for academic research and other noncommercial uses under previous registration (at https://www.tpxo.net/global/tpxo9-atlas); GESLA-2 (Global Extreme Sea Level Analysis Version 2) data set is freely available on the web page https://www.gesla.org. Both the databases and the methods used are extensively described in the "Data for classification and validation" subsection. 


\section{Acknowledgments}

First of all, we thank to Reviewers and Editor for their valuable comments and suggestions to improve the manuscript.

\section{References}

Aubrey, D., \& Friedrichs, C. (1988). Seasonal climatology of tidal non-linearities in a shallow estuary. In D. G. Aubrey \& L. Weishar (Eds.), Hydrodynamics and sediment dynamics of tidal inlets (pp. 103-124). Berlin: Springer.

Aubrey, D., \& Speer, P. (1985). A study of non-linear tidal propagation in shallow inlet/estuarine systems Part I: Observations. Estuarine, Coastal and Shelf Science, 21(2), 185-205.

Balanda, K., \& MacGillivray, H. (1988). Kurtosis: A critical review. The American Statistician, 42(2), 111-119.

Bárcena, J., Camus, P., García, A., \& Álvarez, C. (2015). Selecting model scenarios of real hydrodynamic forcings on mesotidal and macrotidal estuaries influenced by river discharges using K-means clustering. Environmental, Modelling \& Software, 68, 70-82.

Blanton, J., Lin, G., \& Elston, S. (2002). Tidal current asymmetry in shallow estuaries and tidal creeks. Continental Shelf Research, 22(11-13), 1731-1743.

Boon, J., III, \& Byrne, R. (1981). On basin hyposmetry and the morphodynamic response of coastal inlet systems. Marine Geology, 40(1-2), 27-48.

Brown, J., \& Davies, A. (2007). Flood/ebb tidal dominance in an estuary: sediment transport and morphology, Proceedings of 5th IAHR international symposium on river, coastal and estuarine morphodynamics (pp. 17-21). The Netherlands: University of Twente, Enschede.

Bujalesky, G. (1997). Morfodinámica y evolución histórica de la espiga Punta Popper y la boca de mareas del río Grande, Tierra del Fuego. Revista de la Asociación Geológica Argentina, 52(2), 187-201.

Byun, D. S., \& Cho, Y. K. (2006). Double peak-flood current asymmetry in a shallow-water-constituent dominated embayment with a macro-tidal flat. Geophysical Research Letters, 33, L16613. https://doi.org/10.1029/2006GL026967

Camus, P., Mendez, F., Medina, R., \& Cofiño, A. (2011). Analysis of clustering and selection algorithms for the study of multivariate wave climate. Coastal Engineering, 58(6), 453-462.

Castanedo, S., Mendez, F. J., Medina, R., \& Abascal, A. (2007). Long-term tidal level distribution using a wave-by-wave approach. Advances in Water Resources, 30(11), 2271-2282.

Chan, M., \& Archer, A. (2003). Extreme depositional environments: Mega end members in geologic time (Vol. 370). Boulder, CO: Geological Society of America.

Dauvin, J. (2012). Are the eastern and western basins of the English Channel two separate ecosystems? Marine Pollution Bulletin, 64(3), 463-471.

Defant, A. (1961). Physical oceanography (Vol. 1, 598 pp.). New York: Pergamon.

Dronkers, J. (1986). Tidal asymmetry and estuarine morphology. Netherlands Journal of Sea Research, 20(2-3), 117-131.

Egbert, G., \& Erofeeva, S. (2002). Efficient inverse modeling of barotropic ocean tides. Journal of Atmospheric and Oceanic Technology, 19(2), 183-204.

Ferrarin, C., Tomasin, A., Bajo, M., Petrizzo, A., \& Umgiesser, G. (2015). Tidal changes in a heavily modified coastal wetland. Continental Shelf Research, 101, 22-33.

Finotello, A., Canestrelli, A., Carniello, L., Ghinassi, M., \& D'Alpaos, A. (2019). Tidal flow asymmetry and discharge of lateral tributaries drive the evolution of a microtidal meander in the Venice Lagoon (Italy). Journal of Geophysical Research: Earth Surface, 124, 3043-3066. https://doi.org/10.1029/2019JF005193

Friedrichs, C., \& Aubrey, D. (1988). Non-linear tidal distortion in shallow well-mixed estuaries: A synthesis. Estuarine, Coastal and Shelf Science, 27(5), 521-545.

Friedrichs, C., \& Aubrey, D. (1994). Tidal propagation in strongly convergent channels. Journal of Geophysical Research, 99(C2), 3321-3336. Gallo, M., \& Vinzon, S. (2005). Generation of overtides and compound tides in Amazon estuary. Ocean Dynamics, 55(5-6), 441-448.

Guo, L., Wang, Z., Townend, I., \& He, Q. (2019). Quantification of tidal asymmetry and its nonstationary variations. Journal of Geophysical Research: Oceans, 124, 773-787. https://doi.org/10.1029/2018JC014372

Hastie, T., Tibshirani, R., \& Friedman, J. (2001). The elements of statistical learning, Springer series in statistics. New York. (Vol. 1, No. 10).

Hinojosa, I., \& Thiel, M. (2009). Floating marine debris in fjords, gulfs and channels of southern Chile. Marine Pollution Bulletin, 58(3), 341-350.

Hoitink, A., Hoekstra, P., \& Van Maren, D. (2003). Flow asymmetry associated with astronomical tides: Implications for the residual transport of sediment. Journal of Geophysical Research, 108(C10), 3315. https://doi.org/10.1029/2002JC001539

Hoitink, A., Hoekstra, P., \& Van Maren, D. (2006). Comment on "On the role of diurnal tides in contributing to asymmetries in tidal probability distribution functions in areas of predominantly semi-diurnal tide" by PL Woodworth, DL Blackman, DT Pugh and JM Vassie [Estuarine, Coastal and Shelf Science 64 (2005) 235-240]. Estuarine, Coastal and Shelf Science, 67(1-2), 340-341.

Hunter, J., Woodworth, P., Wahl, T., \& Nicholls, R. (2017). Using global tide gauge data to validate and improve the representation of extreme sea levels in flood impact studies. Global and Planetary Change, 156, 34-45.

Jeon, C. H., Buijsman, M. C., Wallcraft, A. J., Shriver, J. F., Arbic, B. K., Richman, J. G., \& Hogan, P. J. (2019). Improving surface tidal accuracy through two-way nesting in a global ocean model. Ocean Modelling, 137, 98-113.

Karsten, R., McMillan, J., Lickley, M., \& Haynes, R. (2008). Assessment of tidal current energy in the Minas Passage, Bay of Fundy. Proceedings of the Institution of Mechanical Engineers, Part A: Journal of Power and Energy, 222(5), 493-507.

Lesser, G. (2009). An approach to medium-term coastal morphological modelling. IHE Delft Institute for Water Education.

Mazarrasa, I., Puente, A., Núñez, P., García, A., Abascal, A., \& Juanes, J. (2019). Assessing the risk of marine litter accumulation in estuarine habitats. Marine Pollution Bulletin, 144, 117-128.

Menéndez, M., \& Woodworth, P. (2010). Changes in extreme high water levels based on a quasi-global tide-gauge data set. Journal of Geophysical Research, 115, C10011. https://doi.org/10.1029/2009JC005997

Monsen, N., Cloern, J., Lucas, L., \& Monismith, S. (2002). A comment on the use of flushing time, residence time, and age as transport time scales. Limnology and Oceanography, 47(5), 1545-1553.

Moore, R., Wolf, J., Souza, A., \& Flint, S. (2009). Morphological evolution of the Dee Estuary, Eastern Irish Sea, UK: A tidal asymmetry approach. Geomorphology, 103(4), 588-596.

Nash, J., \& Sutcliffe, J. (1970). River flow forecasting through conceptual models part IA discussion of principles. Journal of Hydrology, 10(3), 282-290.

Nidzieko, N. (2010). Tidal asymmetry in estuaries with mixed semidiurnal/diurnal tides. Journal of Geophysical Research, 115, C08006. https://doi.org/10.1029/2009JC005864

Nidzieko, N., \& Ralston, D. (2012). Tidal asymmetry and velocity skew over tidal flats and shallow channels within a macrotidal river delta. Journal of Geophysical Research, 117, C03001. https://doi.org/10.1029/2011JC007384 
Núñez, P., García, A., Mazarrasa, I., Juanes, J., Abascal, A., Méndez, F., \& Medina, R. (2019). A methodology to assess the probability of marine litter accumulation in estuaries. Marine Pollution Bulletin, 144, 309-324.

Porter-Smith, R., Harris, P., Andersen, O., Coleman, R., Greenslade, D., \& Jenkins, C. (2004). Classification of the Australian continental shelf based on predicted sediment threshold exceedance from tidal currents and swell waves. Marine Geology, 211(1-2), 1-20.

Ranasinghe, R., \& Pattiaratchi, C. (2000). Tidal inlet velocity asymmetry in diurnal regimes. Continental Shelf Research, 20(17), 2347-2366.

Ridderinkhof, H., van der Ham, R., \& van der Lee, W. (2000). Temporal variations in concentration and transport of suspended sediments in a channel-flat system in the Ems-Dollard estuary. Continental Shelf Research, 20(12-13), 1479-1493.

Song, D., Wang, X., Kiss, A., \& Bao, X. (2011). The contribution to tidal asymmetry by different combinations of tidal constituents. Journal of Geophysical Research, 116, C12007. https://doi.org/10.1029/2011JC007270

Speer, P., \& Aubrey, D. (1985). A study of non-linear tidal propagation in shallow inlet/estuarine systems Part II: Theory. Estuarine, Coastal and Shelf Science, 21(2), 207-224.

Wahl, T., Haigh, I., Nicholls, R., Arns, A., Dangendorf, S., Hinkel, J., \& Slangen, A. (2017). Understanding extreme sea levels for broad-scale coastal impact and adaptation analysis. Nature Communications, 8(1), 1-12.

Westfall, P. (2014). Kurtosis as peakedness, 1905-2014. RIP. The American Statistician, 68(3), 191-195.

Woodworth, P., Blackman, D., Pugh, D., \& Vassie, J. (2005). On the role of diurnal tides in contributing to asymmetries in tidal probability distribution functions in areas of predominantly semi-diurnal tide. Estuarine, Coastal and Shelf Science, 64(2-3), 235-240.

Woodworth, P., Hunter, J., Marcos, M., Caldwell, P., Menéndez, M., \& Haigh, I. (2017). Towards a global higher-frequency sea level dataset. Geoscience Data Journal, 3(2), 50-59.

Zhou, Z., Coco, G., Townend, I., Gong, Z., Wang, Z., \& Zhang, C. (2018). On the stability relationships between tidal asymmetry and morphologies of tidal basins and estuaries. Earth Surface Processes and Landforms, 43(9), 1943-1959. 